\title{
Representation of anatomy in online atlases and databases: a survey and collection of patterns for interface design
}

\author{
Melissa D. Clarkson
}

\begin{abstract}
Background: A large number of online atlases and databases have been developed to mange the rapidly growing amount of data describing embryogenesis. As these community resources continue to evolve, it is important to understand how representations of anatomy can facilitate the sharing and integration of data. In addition, attention to the design of the interfaces is critical to make online resources useful and usable.

Results: I first present a survey of online atlases and gene expression resources for model organisms, with a focus on methods of semantic and spatial representation of anatomy. A total of 14 anatomical atlases and 21 gene expression resources are included. This survey demonstrates how choices in semantic representation, in the form of ontologies, can enhance interface search functions and provide links between relevant information. This survey also reviews methods for spatially representing anatomy in online resources. I then provide a collection of patterns for interface design based on the atlases and databases surveyed. These patterns include methods for displaying graphics, integrating semantic and spatial representations, organizing information, and querying databases to find genes expressed in anatomical structures.

Conclusions: This collection of patterns for interface design will assist biologists and software developers in planning the interfaces of new atlases and databases or enhancing existing ones. They also show the benefits of standardizing semantic and spatial representations of anatomy by demonstrating how interfaces can use standardization to provide enhanced functionality.
\end{abstract}

Keywords: Atlas, Database, Interface, Ontology, Anatomy

\section{Background}

Developmental biology is a data-intensive science. During the last two decades the primary means of archiving and accessing experimental results has shifted from traditional printed publications to digital repositories and web sites $[1,2]$. This transition was driven by the need to mange the rapidly growing amount of data describing embryogenesis, integrate heterogeneous data, represent this data within the context of space and time, and enable cross-species comparisons.

Development of the first digital atlas took place in the early 1990s. These authors constructed a 9-day mouse embryo in 3D using serial sections at histological resolution,

Correspondence: melissa@melissaclarkson.com

Department of Biological Structure, School of Medicine, University of Washington, Seattle, WA, USA with plans to later incorporate spatially-based gene expression data [3]. Since that time, many anatomical atlases and gene expression databases have been developed for a number of species, by both individual laboratories and multi-institution teams.

Development of these resources has required partnering with computer science and informatics researchers. Areas of partnership include not only designing interactive web-based tools and improving methods of image capture and analysis, but also developing standards for data integration. Efforts to standardize elements of research (such as gene nomenclature, experimental protocols, descriptions of phenotypes, and the organisms themselves) began decades before the introduction of digital repositories $[4,5]$. But standards are particularly important for digital repositories because the ability of users to find information relevant to their needs-and to 
make sense of what they find-is determined by the quality and consistency of the data and its annotations.

The Gene Ontology (GO) is a prominent example of an effort to develop semantic standards for molecular biology. GO allows biologists to describe the role of gene products shared across eukaryotic organisms [6]. It is widely used to cluster results of large-scale differential gene expression studies into functional categories, and has an important role in representing and aiding the discovery of gene regulatory networks $[7,8]$.

The representation of anatomy often receives less attention than the representation of genes, but is crucial because studies of gene expression must document not only the genes studied but also the anatomical location(s) of the expression. These annotations are most useful when they represent anatomy in ways that are explicit, standardized, and can be understood by researchers without expert knowledge of the species represented.

Methods for curating information about the anatomy of model organisms have evolved in parallel with methods for disseminating experimental data. Traditional print-based atlases have long been used to document anatomy and standardize terminology for structures and developmental stages. Online atlases provide additional benefits because they (a) allow data such as high-resolution two-dimensional (2D) images, three-dimensional (3D) reconstructions, and movies to be shared, (b) can be updated frequently, and (c) can link to external resources or incorporate content maintained by other sites.

The task of representing an organism's anatomy during development is inherently complex. As shown in Fig. 1, a complete description would account for three-dimensional structure at scales spanning gross, histological, and

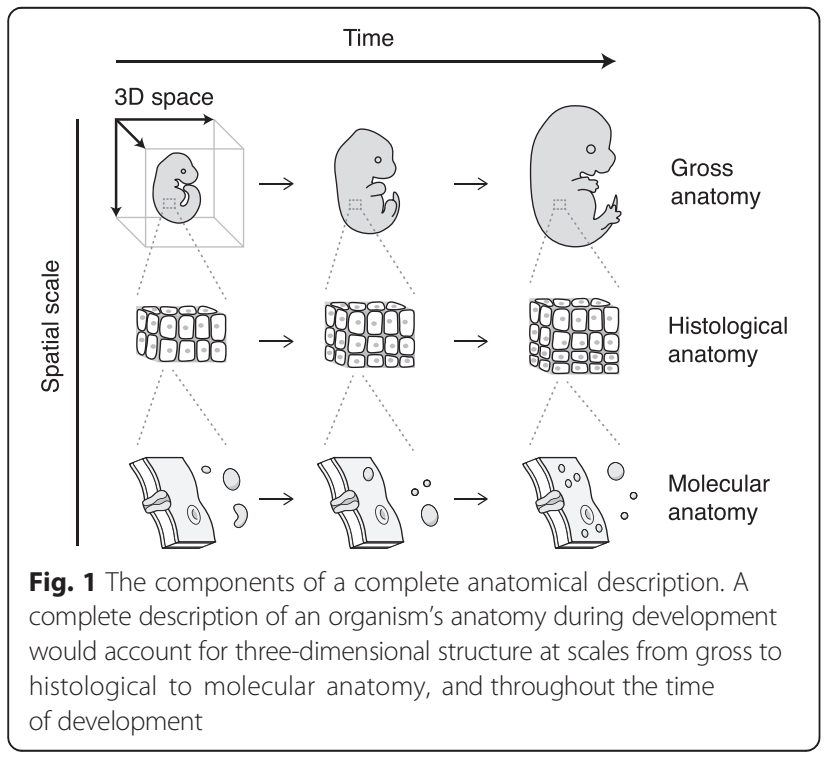

molecular anatomy, each throughout the time of development. Managing knowledge and data within this spacescale-time matrix presents a tremendous challenge. But it is also an opportunity to develop online atlases that not only provide anatomical descriptions, but also use anatomy as a framework for organizing and sharing data [9].

In order to develop atlases that will successfully serve as data portals for developmental biologists, research in a number of areas is crucial. These include development of web technologies for delivering volumetric image data over the web [10] and tools to support comparing data from disparate sources within a common spatial environment $[11,12]$. Work related to gene expression data includes capture of quantitative expression data [13], mapping expression data to 3D graphics [14], visualization of data across time and space [15], and automating annotation of expression patterns with anatomical terms [16]. Atlases could also provide tools to aid researchers in analysis of their own data, such as feature for more precisely describing a specimen's stage based on interpolating between reference stages $[17,18]$.

Atlases serving as data portals will require tightly integrated spatial and semantic representations as users alternate between image-based and term-based navigation and data retrieval. Therefore, in addition to research rooted in the fields of computer science and informatics, expertise is also needed from the fields of interaction design (to develop intuitive interfaces and effective visualizations) and knowledge representation (to provide semantic representations to enable data integration).

As shown in Fig. 2, the type of semantic representation determines the level of meaning captured within the representation. A controlled vocabulary is a list of terms within a specific domain. A taxonomy is a controlled vocabulary with hierarchical is_a relationships. An ontology is a taxonomy with additional relationships such as has_part and develops_into. The information provided by these relationships is necessary for developing atlases that link together data across space and time.

This article examines online resources for developmental biologists with an emphasis on semantic and spatial representation and interface design. I first survey 14 anatomical atlases and 21 gene expression resources for methods of anatomical representation. I then present a collection of patterns for interface design that demonstrate the variety of approaches used for anatomical representation, user interaction, and navigation with the atlases and databases. The purposes of this work are to (a) assist biologists and software developers in planning the interfaces of new atlases and databases or enhancing existing ones, and (b) demonstrate the benefits of standardizing semantic and spatial representations of anatomy. 


\begin{tabular}{|l|c|}
\multicolumn{1}{|c|}{ Controlled vocabulary } & \multicolumn{1}{c}{ Taxonomy } \\
\cline { 2 - 2 } Hindlimb & Anatomical structure \\
Right hindlimb & Hindlimb \\
Left hindlimb & Right hindlimb \\
Forelimb & Left hindlimb \\
Right forelimb & Forelimb \\
Left forelimb & Right forelimb \\
Hand & Left forelimb \\
Right hand & Hand \\
Left hand & Right hand \\
Foot & Left hand \\
Right foot & Foot \\
Left foot & Right foot \\
& Left foot \\
\hline
\end{tabular}

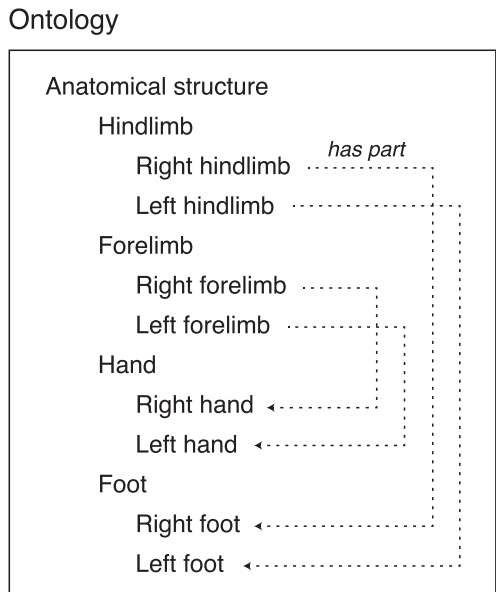

Fig. 2 Levels of complexity in semantic representation. A controlled vocabulary is a list of defined terms. A taxonomy is a controlled vocabulary with a hierarchical structure formed by is_a relationships between pairs of terms. An ontology is a taxonomy with additional relationships, such as part_of

\section{Results}

\section{Anatomical atlases}

For the purpose of this work, an anatomical atlas is defined as a resource that provides spatial representations of a body or region of a body, plus a set of anatomical terms which are associated with regions of the representations. I identified 14 online anatomical atlases describing organisms commonly used by developmental biologists.

Descriptions of each atlas are provided in Table 1. The six species represented (and number of atlases for each) are Caenorhabditis elegans (two), Ciona intestinalis (two), Drosophila (two), medaka (one), mouse (two), and zebrafish (four). Eight atlases have a spatial scope of the entire body, while others are limited to the brain (Drosophila, mouse), vasculature (medaka, zebrafish), midgut (Drosophila), or craniofacial skeleton (zebrafish). With the exception of one atlases for $C$. elegans and both Drosophila atlases, all atlases include a description of at least some developmental stages.

Table 2 lists the types of anatomical representations used within each atlas. Types of graphics included confocal micrographs, transmission electron micrographs (TEMs), histological sections, 3D reconstructions from histological sections, 3D surface models, illustrations, and brightfield movies. Six of the atlases stated that a controlled vocabulary or ontology was used as a source of terms for anatomical structures.

\section{Gene expression atlases and databases}

For this work, a gene expression atlas or database is defined as a resource that combines evidence of gene expression with a representation of the anatomical region of the expression. Because this work emphasizes spatial representations, resources consisting only of microarray data were excluded. I identified 21 resources for gene expression.

Descriptions of each atlas or database for gene expression are provided in Table 3. The eight species represented (and number of resources for each) are Caenorhabditis elegans (two), chicken (one), Ciona intestinalis (one), Drosophila (four), medaka (one), mouse (eight), Хenopus (two), and zebrafish (two). The spatial scope for 18 of the resources is the entire body. Others are limited to brain, nervous system, or urogenital system (each for the mouse). All resources include at least one developmental stage.

Table 4 lists the anatomical representations used within each gene expression atlas or database. Types of graphics documenting expression patterns include brightfield micrographs showing a colorimetric assay for expression in both histological sections and whole mounts, confocal micrographs, and 3D models with the region of expression highlighted. At least eight of the resources rely primarily on submissions of data from the community, and therefore various types of graphics are presented across different database entries. All resources use anatomical terms to describe regions of expression. However, only 14 use terms from controlled vocabularies or ontologies. The other resources appear to use projectspecific vocabularies.

\section{Semantic representation: Controlled vocabularies and ontologies}

Table 5 lists the controlled vocabularies and ontologies used in the resources surveyed. This survey revealed that a total of 12 vocabularies or ontologies are used. Each includes terms relevant to adult 
Table 1 Summary of anatomical atlases surveyed

\begin{tabular}{|c|c|c|c|c|c|}
\hline Atlas & Description & $\begin{array}{l}\text { Spatial } \\
\text { scope }\end{array}$ & Developmental stages & URL, full project name, project leadership & Publication \\
\hline \multicolumn{6}{|l|}{ C. elegans } \\
\hline WormAtlas & $\begin{array}{l}\text { A collection of resources including the SlidableWorm (for viewing } \\
\text { annotated electron micrograph sections) and descriptions of } \\
\text { individual neurons. }\end{array}$ & body & $\begin{array}{l}\text { adult hermaphrodite, adult } \\
\text { male, dauer larva }\end{array}$ & $\begin{array}{l}\text { http://wormatlas.org } \\
\text { From the laboratory of David Hall at } \\
\text { Albert Einstein College of Medicine } \\
\text { (Bronx, NY, USA). }\end{array}$ & [45] \\
\hline $\begin{array}{l}\text { OpenWorm Browser } \\
\text { (Virtual Worm) }\end{array}$ & $\begin{array}{l}\text { A 3D virtual reconstruction } \\
\text { consisting of surface models of } \\
680 \text { cells. }\end{array}$ & body & adult only & $\begin{array}{l}\text { http://browser.openworm.org } \\
\text { A collaboration between WormBase } \\
\text { and OpenWorm. }\end{array}$ & [46] \\
\hline \multicolumn{6}{|l|}{ Ciona intestinalis } \\
\hline $\begin{array}{l}\text { ANISEED } \\
\text { ("Anatomy" section) }\end{array}$ & $\begin{array}{l}\text { Illustrations of ascidian embryos at selected stages, annotated with } \\
\text { cell names. }\end{array}$ & body & egg through adult & $\begin{array}{l}\text { http://www.aniseed.cnrs.fr } \\
\text { Ascidian Network for In Situ and } \\
\text { Embryological Data } \\
\text { A collaboration among ascidian } \\
\text { researchers led by Patrick Lemaire } \\
\text { at the CRM (Montpellier, France). }\end{array}$ & $\begin{array}{l}{[47]} \\
{[48]}\end{array}$ \\
\hline FABA & $\begin{array}{l}\text { Confocal micrographs for } \\
\text { standardizing developmental stages. }\end{array}$ & body & $\begin{array}{l}\text { zygote through hatched } \\
\text { larva }\end{array}$ & $\begin{array}{l}\text { http://tunicate-portal.org/faba/1.4/top.html } \\
\text { Four-dimensional Ascidian Body Atlas } \\
\text { From the laboratory of Kohji Hotta at } \\
\text { Keio University (Yokohama, Japan). }\end{array}$ & [49] \\
\hline \multicolumn{6}{|l|}{ Drosophila } \\
\hline Flygut & $\begin{array}{l}\text { Description of the Drosophila midgut based on anatomy, histology, and } \\
\text { expression patterns of reporter transgenes. }\end{array}$ & midgut & adult only & $\begin{array}{l}\text { http://flygut.epfl.ch } \\
\text { This atlas complements a publication } \\
\text { from Bruno Lemaitre's group at EPFL } \\
\text { (Lausanne, Switzerland). }\end{array}$ & {$[50]$} \\
\hline Virtual Fly Brain & $\begin{array}{l}\text { Virtual sections from a reference } \\
\text { brain, with anatomical regions } \\
\text { delineated. }\end{array}$ & brain & adult only & $\begin{array}{l}\text { http://www.virtualflybrain.org } \\
\text { Members of the Virtual Fly Brain team } \\
\text { are from the University of Edinburgh } \\
\text { (Edinburgh, Scotland) and the University } \\
\text { of Cambridge (Cambridge, England). }\end{array}$ & [51] \\
\hline \multicolumn{6}{|l|}{ Medaka } \\
\hline Medaka Blood Vessel Atlas & $\begin{array}{l}\text { Annotated illustrations of the } \\
\text { vasculature of embryos. }\end{array}$ & vasculature & mid-embryonic stages & $\begin{array}{l}\text { http://www.shigen.nig.ac.jp/medaka/ } \\
\text { medaka_atlas } \\
\text { Work by Misato Fujita and Sumio Isogai. } \\
\text { Hosted online by the National BioResource } \\
\text { Project Medaka (Japan). }\end{array}$ & $\begin{array}{l}{[52]} \\
{[53]}\end{array}$ \\
\hline \multicolumn{6}{|l|}{ Mouse } \\
\hline $\begin{array}{l}\text { Allen Developing Mouse } \\
\text { Brain Reference Atlas }\end{array}$ & $\begin{array}{l}\text { Histological sections of brain with } \\
\text { anatomical regions delineated. }\end{array}$ & brain & $\begin{array}{l}\text { four embryonic stages, four } \\
\text { post-natal stages }\end{array}$ & $\begin{array}{l}\text { http://developingmouse.brain-map.org/ } \\
\text { static/atlas } \\
\text { Produced by the Allen Institute for Brain } \\
\text { Sciences (Seattle, WA, USA). }\end{array}$ & $\begin{array}{l}{[54]} \\
{[55]}\end{array}$ \\
\hline
\end{tabular}


Table 1 Summary of anatomical atlases surveyed (Continued)

e-Mouse Atlas

$3 \mathrm{D}$ reconstructions of embryos (some with anatomical regions delineated), histological sections, and a guide to embryological stages.

Zebrafish

FishFace

Graphics of fluorescently-labeled chondrocytes, osteoblasts, and bone matrix in the first two pharyngeal arches.

FishNet

Virtual sections from optical projection tomography (OPT) scans (with selected section annotated).

Interactive Atlas of Zebrafish Fluorescent angiograms as movies Vascular Anatomy and annotated diagrams. body

all embryonic stages, three post-natal stages

\section{ee htp}

http://www.emouseatlas.org/emap/ema/ home.html also known as the Edinburgh Mouse Atlas

Project led by Duncan Davidson

of Edinburgh (Edinburgh, Scotland). craniofacial pharyngula through skeleton adult

body

pharyngula through adult

vasculature pharyngula through larva

body

body https://www.facebase.org/fishface/home Created by the laboratory of Charles Kimmel at the University of Oregon (Eugene, OR, USA) as part of the FaceBase Consortium (USA).

http://www.fishnet.org.au

Produced by Robert Bryson-Richardson and Peter Currie at Monash University (Clayton, VIC, Australia).

http://zfish.nichd.nih.gov/Intro\%20Page/ intro1.html

Produced by Brant Weinstein's group at the National Institutes of Health (Bethesda MD, USA).

http://zebrafish.anatomyportal.org

Zebrafish Anatomy Portal

From Robert Bryson-Richardson's group

at Monash University (Clayton, VIC, Australia).

http://bio-atlas.psu.edu/zf

From the laboratory of Keith Cheng at

Penn State College of Medicine (Hershey,

PA, USA). 
Table 2 Anatomical representations within the anatomical atlas

\begin{tabular}{|c|c|c|}
\hline & Types of graphics ${ }^{a}$ & $\begin{array}{l}\text { Controlled vocabulary or ontology for } \\
\text { anatomy }\end{array}$ \\
\hline \multicolumn{3}{|l|}{ C. elegans } \\
\hline WormAtlas & $\begin{array}{l}\text { - TEMs } \\
\text { - illustrations } \\
\text { - DIC micrographs } \\
\text { - fluorescence micrographs } \\
\text { - confocal micrographs (as movies of volumes) } \\
\text { - various movies, including 3D reconstructions from } \\
\text { ssTEMs }\end{array}$ & not stated \\
\hline $\begin{array}{l}\text { OpenWorm Browser } \\
\text { (Virtual Worm) }\end{array}$ & - 3D surface models & not stated \\
\hline \multicolumn{3}{|l|}{ Ciona intestinalis } \\
\hline ANISEED ("Anatomy" section) & - illustrations & Ciona Developmental Ontology \\
\hline FABA & $\begin{array}{l}\text { - confocal micrographs (as virtual sections and } \\
\text { volumes) } \\
\text { - brightfield movies }\end{array}$ & not stated ${ }^{b}$ \\
\hline \multicolumn{3}{|l|}{ Drosophila } \\
\hline Flygut & $\begin{array}{l}\text { - schematic illustrations } \\
\text { - fluorescence micrographs } \\
\text {-3D surface models }\end{array}$ & not stated \\
\hline Virtual Fly Brain & $\begin{array}{l}\text { - confocal micrographs (as virtual sections) } \\
\text {-3D surface models of neurons }\end{array}$ & Drosophila Anatomy Ontology ${ }^{c}$ \\
\hline \multicolumn{3}{|l|}{ Medaka } \\
\hline Medaka Blood Vessel Atlas & $\begin{array}{l}\text { - illustrations } \\
\text { - confocal microangiographs }\end{array}$ & not stated \\
\hline \multicolumn{3}{|l|}{ Mouse } \\
\hline $\begin{array}{l}\text { Allen Developing Mouse Brain Reference } \\
\text { Atlas }\end{array}$ & - histological sections with illustration overlays & Developing Mouse Brain Atlas ontology \\
\hline e-Mouse Atlas & $\begin{array}{l}\text { - } 3 \text { D reconstructions of histological sections } \\
\text { (as virtual sections and volumes) } \\
\text { - histological sections } \\
\text { - OPT scans (as volumes) } \\
\text { - illustrations of stages }\end{array}$ & EMAP anatomy ontology \\
\hline \multicolumn{3}{|l|}{ Zebrafish } \\
\hline FishFace & $\begin{array}{l}\text { - confocal micrographs (as projections) } \\
\text { - OPT scans (as volumes) }\end{array}$ & Zebrafish Anatomy Ontology and [67] \\
\hline FishNet & - OPT scans (as virtual sections and volumes) & not stated \\
\hline $\begin{array}{l}\text { Interactive Atlas of Zebrafish Vascular } \\
\text { Anatomy }\end{array}$ & $\begin{array}{l}\text { - illustrations } \\
\text { - confocal microangiographs (as projections and } \\
\text { volumes) }\end{array}$ & reference list on website \\
\hline ZFAP & - OPT scans (as virtual sections and volumes) & Zebrafish Anatomy Ontology \\
\hline Zebrafish Atlas & - histological sections & term list on website \\
\hline
\end{tabular}

a Abbreviations: DIC differential inference contrast, TEM transmission electron micrograph, ssTEM serial section transmission electron micrograph, OPT optical projection tomography

${ }^{\mathrm{b}}$ The FABA established the developmental stages used in the Ciona Developmental Ontology

c The vocabulary from the Insect Brain Name Working Group [68] was incorporated into the Drosophila Anatomy Ontology as part of the development of the Virtual Fly Brain atlas

anatomy, developmental anatomy and stages, or both. Seven organisms are represented (C. elegans, $C$. intestinalis, Drosophila, medaka, mouse, Xenopus, and zebrafish). As shown in Table 5 (third column, indicated with superscript), each vocabulary and ontology was developed by one of the groups creating an atlas or database included in Tables 1 and 3.
Several atlases and gene expression resources demonstrate how the relationships within ontologies can contribute to the usefulness of interfaces by enhancing search functions or providing links between relevant information:

Part relationships: EMAGE [19] and GXD [20] are databases for gene expression in the mouse, and both 
Table 3 Summary of gene expression atlases and databases surveyed

\begin{tabular}{|c|c|c|c|c|c|}
\hline Atlas or database & Description & Spatial scope & Developmental stages & URL, full project name, project leadership & Publication \\
\hline \multicolumn{6}{|l|}{ C. elegans } \\
\hline $\begin{array}{l}\text { Expression patterns for } C \text {. elegans } \\
\text { promoter::GFP fusions }\end{array}$ & $\begin{array}{l}\text { Database of expression } \\
\text { patterns of transgenic } \\
\text { animals with promoter:: } \\
\text { GFP fusions }\end{array}$ & body & embryo through adult & $\begin{array}{l}\text { http://gfpweb.aecom.yu.edu/index } \\
\text { A project of the British Columbia } \\
\text { C. elegans Gene Expression Consortium }\end{array}$ & [69] \\
\hline WormBase ("WormMine" tool) & $\begin{array}{l}\text { Community repository of } \\
\text { molecular and genetic } \\
\text { data from the literature, } \\
\text { submissions, and } \\
\text { collaborating projects }\end{array}$ & body & embryo through adult & $\begin{array}{l}\text { http://www.wormbase.org } \\
\text { An international consortium of researchers, } \\
\text { based at Caltech (Pasadena, CA, USA) }\end{array}$ & $\begin{array}{l}{[70]} \\
{[46]}\end{array}$ \\
\hline \multicolumn{6}{|l|}{ Chicken } \\
\hline GEISHA & $\begin{array}{l}\text { Community repository of } \\
\text { in situ hybridization data } \\
\text { acquired from high- } \\
\text { throughput screens and } \\
\text { the literature }\end{array}$ & body & $\begin{array}{l}\text { egg through first six days } \\
\text { of development }\end{array}$ & $\begin{array}{l}\text { http://geisha.arizona.edu/geisha } \\
\text { Gallus Expression in Situ Hybridization Analysis } \\
\text { Hosted by Parker Antin's group at the } \\
\text { University of Arizona (Tuscaon, AZ, USA) }\end{array}$ & $\begin{array}{l}{[71]} \\
{[72]} \\
{[73]}\end{array}$ \\
\hline \multicolumn{6}{|l|}{ Ciona intestinalis } \\
\hline $\begin{array}{l}\text { ANISEED ("Gene Expression \& } \\
\text { Function" section) }\end{array}$ & $\begin{array}{l}\text { Community repository of } \\
\text { expression data from the } \\
\text { literature, submissions, } \\
\text { and collaborating projects }\end{array}$ & body & egg through adult & $\begin{array}{l}\text { http://www.aniseed.cnrs.fr } \\
\text { Ascidian Network for In Situ and } \\
\text { Embryological Data } \\
\text { A collaboration among ascidian researchers } \\
\text { led by Patrick Lemaire at the CRM } \\
\text { (Montpellier, France) }\end{array}$ & $\begin{array}{l}{[47]} \\
{[48]}\end{array}$ \\
\hline \multicolumn{6}{|l|}{ Drosophila } \\
\hline BDGP expression patterns & $\begin{array}{l}\text { Database of in situ } \\
\text { hybridization patterns }\end{array}$ & body & all embryonic stages & $\begin{array}{l}\text { http://insitu.fruitfly.org/cgi-bin/ex/insitu.pl } \\
\text { Berkeley Drosophila Genome Project } \\
\text { From the laboratory of Susan Celniker at the } \\
\text { Lawrence Berkeley Laboratory (Berkeley, CA, USA) }\end{array}$ & $\begin{array}{l}{[74]} \\
{[75]} \\
{[76]}\end{array}$ \\
\hline FlyBase ("QuickSearch" tool) & $\begin{array}{l}\text { Community repository of } \\
\text { molecular and genetic } \\
\text { data from the literature } \\
\text { and direct submissions }\end{array}$ & body & egg through adult & $\begin{array}{l}\text { http://flybase.org } \\
\text { From an international consortium of } \\
\text { Drosophila researchers }\end{array}$ & $\begin{array}{l}{[77]} \\
{[78]} \\
{[79]}\end{array}$ \\
\hline FlyExpress & $\begin{array}{l}\text { A tool for searching } \\
\text { expression patterns using } \\
\text { images data from BDGP } \\
\text { and Fly-FISH }\end{array}$ & body & all embryonic stages & $\begin{array}{l}\text { http://www.flyexpress.net } \\
\text { From the laboratory of Sudhir Kumar at } \\
\text { Arizona State University (Tempe, AZ, USA) }\end{array}$ & $\begin{array}{l}{[40]} \\
{[80]}\end{array}$ \\
\hline Fly-FISH & $\begin{array}{l}\text { Database of in situ } \\
\text { hybridization patterns }\end{array}$ & body & $\begin{array}{l}\text { early embryonic stages and } \\
\text { third instar larva }\end{array}$ & $\begin{array}{l}\text { http://fly-fish.ccbr.utoronto.ca } \\
\text { From the laboratory of Henry Krause at the } \\
\text { University of Toronto (Toronto, Ontario, Canada) }\end{array}$ & [81] \\
\hline
\end{tabular}

University of Toronto (Toronto, Ontario, Canada) 
Table 3 Summary of gene expression atlases and databases surveyed (Continued)

Medaka

MEPD

Database of expression patterns for genes (in

regulatory sequences

(fluorescent reporters)

Mouse

Allen Developing Mouse Brain Atlas ("AGEA" section)

Atlas of spatially correlated expression patterns derived from in situ hybridizations on histological sections

EMBRYS

Database of in situ hybridization patterns, using whole mounts

EMAGE

Community repository of molecular and genetic data from the literature and direct submissions

\section{Eurexpress}

Database of in situ

hybridization patterns,

using histoloogical sections

GENSAT

GenePaint

GUDMAP

Community repository of expression data from the literature, direct submissions, and collaborating projects

Database of in situ

hybridization patterns and data from transgenic mice with EGFP r

Database of in situ

hybridization patterns,

using histological sections

Community repository of body

egg through adult

brain

four embryonic stages (E11.5, 13.5, 15.5, 18.5)

four post-natal stages

$(P 4,14,28)$

body expression data from the GUDMAP consortium

three embryonic stag (E9.5, 10.5, 11.5)

all post-implantation stages

one embryonic stage (E14.5) body

nervous system

body

urogenital system

http://mepd.cos.uni-heidelberg.de/mepd

Medaka Expression Pattern Database

A project within the Medaka Genome

Initiative, from the laboratory of Joachin

Wittbrody at University of Heidelberg

Heidelberg, Germany)

http://developingmouse.brain-map.org/

agea/show

Anatomic Gene Expression Atlas of the Allen

Developing Mouse Brain Atlas

Produced by the Allen Institute for Brain

Sciences (Seattle, WA, USA)

http://embrys.jp/embrys/html/MainMenu.htm

all embryonic stages, postnatal

one embryonic stage (E15.5), postnatal (P7), adult

three embryonic stages (E10.5, 14.5, 15.5), postnatal (P7), adult

mid-embryonic development through adult Note: no longer available online

From the laboratory of Hiroshi Asahara at the Systems BioMedicine Laboratory of the National Research Institute for Child Health and Development (Tokyo, Japan)

http://www.emouseatlas.org/emage/home.php e-Mouse Atlas of Gene Expression Led by Duncan Davidson and Richard Baldock within the Medical Research Council Human Genetics Unit at the University of

Edinburgh (Edinburgh, Scotland)

http://www.eurexpress.org/ee

From a consortium of European researchers

http://www.informatics.jax.org/gxd

Mouse Gene Expression Database

A Mouse Genome Informatics resource from Jackson Laboratory (Bar Harbor, ME, USA)

http://www.gensat.org/index.html

Gene Expression Nervous System Atlas

From the laboratory of Nathaniel Heinz

The Rockefeller University (New York, NY, USA)

http://genepaint.org

Led by Gregor Eichele at the Max Planck

Institute of Biophysical Chemistry (Göttingen,

Germany)

http://www.gudmap.org

GenitoUrinary Molecular Anatomy Project

From an international consortium of researchers 
Table 3 Summary of gene expression atlases and databases surveyed (Continued)

Xenopus

Xenbase

XenMARK expression patterns expression data from the

literature, submissions, and

collaborating projects

\section{Database of in situ}

hybridization patterns,

using whole mounts

Zebrafish

GEMS

Database of in situ

hybridization patterns

ZFIN

Community repository

of molecular and genetic

data from literature and

direct submissions body

body

body

body all stages through adult

2-cell stage through tadpole

the
hittp.//genomics.crick.ac.uk/apps/XenMARK
From the laboratory of Michael Gilchrist at
the MRC National Institute for Medical

Research (London, UK)

http://bio-imaging.liacs.nl/liacsgems.html

Note: no longer available online

Gene Expression Management System

Produced by the Imagery \& Media Group

at Leiden University (Leiden, Netherlands)

http://zfin.org

Zebrafish Model Organism Database (also

known as the Zebrafish Information Network)

Based at the University of Oregon (Eugene, OR, USA)
[105]

[108]

[109]

[110] 
Table 4 Anatomical representations within the gene expression atlases and databases

\begin{tabular}{|c|c|c|}
\hline Atlas or database & Types of graphics ${ }^{a}$ & Controlled vocabulary or ontology for anatomy ${ }^{b}$ \\
\hline \multicolumn{3}{|l|}{ C. elegans } \\
\hline $\begin{array}{l}\text { Expression patterns for C. elegans } \\
\text { promoter::GFP fusions }\end{array}$ & $\begin{array}{l}\text { - fluorescence micrographs } \\
\text { - confocal micrographs (as projections and volumes) } \\
\text { - DIC micrographs with fluorescence overlays }\end{array}$ & project-specific vocabulary \\
\hline WormBase ("WormMine" tool) & $\begin{array}{l}\text { - various types submitted } \\
\text { - Virtual Worm model with regions of gene } \\
\text { expression highlighted }\end{array}$ & $\begin{array}{l}\text { C. elegans Gross Anatomy Vocabulary } \\
\text { C. elegans Development Vocabulary }\end{array}$ \\
\hline \multicolumn{3}{|l|}{ Chicken } \\
\hline GEISHA & - various types submitted & project-specific vocabulary \\
\hline \multicolumn{3}{|l|}{ Ciona intestinalis } \\
\hline ANISEED (Expression Data section) & - various types submitted & Ciona Developmental Ontology \\
\hline \multicolumn{3}{|l|}{ Drosophila } \\
\hline BDGP expression patterns & $\begin{array}{l}\text { - brightfield micrographs (whole mounts, } \\
\text { colorimetric assay) }\end{array}$ & Drosophila Anatomy Ontology \\
\hline FlyBase ("QuickSearch" tool) & - & Drosophila Anatomy Ontology \\
\hline FlyExpress & - graphics from BDGP and Fly-FISH & vocabularies from BDGP and Fly-FISH \\
\hline Fly-FISH & - confocal micrographs & project-specific vocabulary \\
\hline \multicolumn{3}{|l|}{ Medaka } \\
\hline MEPD & $\begin{array}{l}\text { - brightfield micrographs (whole mounts, } \\
\text { colorimetric assay for gene expression) } \\
\text { - fluorescence micrographs (for regulatory } \\
\text { element expression) }\end{array}$ & MFO \\
\hline \multicolumn{3}{|l|}{ Mouse } \\
\hline $\begin{array}{l}\text { Allen Developing Mouse Brain } \\
\text { Atlas ("AGEA" section) }\end{array}$ & $\begin{array}{l}\text { - brightfield micrographs (histological } \\
\text { sections, colorimetric assay) } \\
\text { - standardized 3D brain models with regions } \\
\text { of expression highlighted }\end{array}$ & Allen Developing Mouse Brain Atlas ontology \\
\hline EMBRYS & $\begin{array}{l}\text { - brightfield micrographs (whole mounts, } \\
\text { colorimetric assay) } \\
\text { - AERO images (whole mounts, } \\
\text { colorimetric assay) }\end{array}$ & project-specific vocabulary \\
\hline EMAGE & - various types submitted & EMAP anatomy ontology \\
\hline Eurexpress & $\begin{array}{l}\text { - brightfield micrographs (histological sections, } \\
\text { colorimetric assay) }\end{array}$ & EMAP anatomy ontology \\
\hline GXD & - various types submitted & $\begin{array}{l}\text { EMAP anatomy ontology; } \\
\text { MA }\end{array}$ \\
\hline GENSAT & $\begin{array}{l}\text { - brightfield micrographs (histological sections, } \\
\text { colorimetric assay) } \\
\text { - confocal micrographs }\end{array}$ & project-specific vocabulary \\
\hline GenePaint & $\begin{array}{l}\text { - brightfield micrographs (histological sections, } \\
\text { colorimetric assay) }\end{array}$ & project-specific vocabulary \\
\hline GUDMAP & - various types submitted & EMAP anatomy ontology \\
\hline \multicolumn{3}{|l|}{ Xenopus } \\
\hline Xenbase & - various types submitted & XAO \\
\hline XenMARK expression patterns & $\begin{array}{l}\text { - brightfield micrographs (whole mounts, } \\
\text { colorimetric assay) }\end{array}$ & project-specific vocabulary \\
\hline \multicolumn{3}{|l|}{ Zebrafish } \\
\hline GEMS & - confocal micrographs & $\mathrm{DAOZ}$ \\
\hline ZFIN & - various types submitted & ZAO \\
\hline
\end{tabular}

abbreviations: DIC differential inference contrast, AERO images are a series of 2D images captured at 2-degree intervals [88]

b Abbreviations: DAOZ Developmental Anatomy Ontology of Zebrafish, MFO Medaka Fish Anatomy and Development Ontology, XAO Xenopus Anatomy Ontology, ZAO Zebrafish Anatomy Ontology 
Table 5 Controlled vocabularies and ontologies relevant to this survey

\begin{tabular}{|c|c|c|c|c|}
\hline Vocabulary or ontology & Domain & $\begin{array}{l}\text { Used by this atlas } \\
\text { or database }\end{array}$ & URL, full name & Publication \\
\hline \multicolumn{5}{|l|}{ C. elegans } \\
\hline $\begin{array}{l}\text { C. elegans Gross Anatomy } \\
\text { Vocabulary }\end{array}$ & $\begin{array}{l}\text { - developmental and adult } \\
\text { anatomy, including } \\
\text { individual cells }\end{array}$ & WormBase $^{a}$ & $\begin{array}{l}\text { http://bioportal.bioontology.org/ontologies/ } \\
\text { WB-BT also known as the C. elegans Cell and } \\
\text { Anatomy Ontology }\end{array}$ & [111] \\
\hline $\begin{array}{l}\text { C. elegans Development } \\
\text { Vocabulary }\end{array}$ & $\begin{array}{l}\text { - developmental stages } \\
\text { - time points }\end{array}$ & WormBase $^{a}$ & $\begin{array}{l}\text { http://bioportal.bioontology.org/ontologies/ } \\
\text { WB-LS }\end{array}$ & - \\
\hline \multicolumn{5}{|l|}{ Ciona intestinalis } \\
\hline $\begin{array}{l}\text { Ciona intestinalis Anatomy } \\
\text { and Development Ontology }\end{array}$ & $\begin{array}{l}\text { - developmental and adult } \\
\text { anatomy, including individual cells } \\
\text { - developmental stages }\end{array}$ & ANISEED ${ }^{a}$ & $\begin{array}{l}\text { http://bioportal.bioontology.org/ontologies/ } \\
\text { CIINTEADO }\end{array}$ & $\begin{array}{l}{[47]} \\
{[48]}\end{array}$ \\
\hline \multicolumn{5}{|l|}{ Drosophila } \\
\hline $\begin{array}{l}\text { Drosophila Anatomy } \\
\text { Ontology }\end{array}$ & $\begin{array}{l}\text { - developmental and adult anatomy } \\
\text { - includes vocabulary from } \\
\text { the Insect Brain Name Working } \\
\text { Group }\end{array}$ & $\begin{array}{l}\text { VFB } \\
\text { FlyBase }^{a}\end{array}$ & $\begin{array}{l}\text { http://bioportal.bioontology.org/ontologies/ } \\
\text { FB-BT also known as the Drosophila Gross } \\
\text { Anatomy Ontology }\end{array}$ & $\begin{array}{l}{[68]} \\
{[27]} \\
{[112]}\end{array}$ \\
\hline $\begin{array}{l}\text { Drosophila Development } \\
\text { Ontology }\end{array}$ & $\begin{array}{l}\text { - developmental stages } \\
\text { - cycles of nuclear division }\end{array}$ & FlyBase $^{a}$ & $\begin{array}{l}\text { http://bioportal.bioontology.org/ontologies/FB- } \\
\text { DV }\end{array}$ & - \\
\hline \multicolumn{5}{|l|}{ Medaka } \\
\hline MFO & $\begin{array}{l}\text { - developmental and adult anatomy } \\
\text { - developmental stages }\end{array}$ & $\mathrm{MEPD}^{\mathrm{a}}$ & $\begin{array}{l}\text { http://bioportal.bioontology.org/ontologies/ } \\
\text { MFO } \\
\text { Medaka Fish Anatomy and Development } \\
\text { Ontology }\end{array}$ & [83] \\
\hline \multicolumn{5}{|l|}{ Mouse } \\
\hline MA & - adult anatomy & GXD & $\begin{array}{l}\text { http://bioportal.bioontology.org/ontologies/MA } \\
\text { Adult Mouse Anatomy, } \\
\text { also known as the Mouse Adult Gross } \\
\text { Anatomy Ontology }\end{array}$ & [22] \\
\hline $\begin{array}{l}\text { Allen Developing Mouse } \\
\text { Brain Atlas ontology }\end{array}$ & - developmental anatomy & $\begin{array}{l}\text { Allen Developing } \\
\text { Mouse Brain Atlas }\end{array}$ & $\begin{array}{l}\text { http://help.brain-map.org/display/api/Atlas } \\
\text { +Drawings+and+Ontologies }\end{array}$ & {$[55]$} \\
\hline EMAP & $\begin{array}{l}\text { - developmental anatomy } \\
\text { - includes vocabulary from } \\
\text { the GUDMAP consortium }\end{array}$ & $\begin{array}{l}\text { e-Mouse Atlas } \\
\text { GXD } \\
\text { GUDMAP }\end{array}$ & $\begin{array}{l}\text { http://bioportal.bioontology.org/ontologies/ } \\
\text { EMAP } \\
\text { e-Mouse Atlas Project anatomy ontology }\end{array}$ & $\begin{array}{l}{[21]} \\
{[113]} \\
{[114]}\end{array}$ \\
\hline \multicolumn{5}{|l|}{ Xenopus } \\
\hline XAO & $\begin{array}{l}\text { - developmental and adult anatomy } \\
\text { - developmental stages }\end{array}$ & Xenbase ${ }^{a}$ & $\begin{array}{l}\text { http://bioportal.bioontology.org/ontologies/XAO } \\
\text { Xenopus Anatomy Ontology, also known as the } \\
\text { Xenopus Anatomy and Development Ontology }\end{array}$ & $\begin{array}{l}{[24]} \\
{[115]}\end{array}$ \\
\hline \multicolumn{5}{|l|}{ Zebrafish } \\
\hline $\mathrm{DAOZ}$ & $\begin{array}{l}\text { - developmental anatomy } \\
\text { - developmental stages }\end{array}$ & $\mathrm{GEMS}^{\mathrm{a}}$ & $\begin{array}{l}\text { http://bio-imaging.liacs.nl/liacsontology.html } \\
\text { Developmental Anatomy Ontology of Zebrafish }\end{array}$ & {$[116]$} \\
\hline ZFA & $\begin{array}{l}\text { - developmental and adult } \\
\text { anatomy } \\
\text { - developmental stages }\end{array}$ & ZFIN & $\begin{array}{l}\text { http://bioportal.bioontology.org/ontologies/ZFA } \\
\text { Zebrafish Anatomy Ontology, also known as the } \\
\text { Zebrafish Anatomy and Development Ontology }\end{array}$ & [117] \\
\hline
\end{tabular}

${ }^{a}$ The vocabulary or ontology was developed by the group constructing this atlas or database

have a search function that accepts a term for an anatomical structure and returns genes expressed in that structure. These databases make use of the part hierarchies in the EMAP anatomy ontology [21] and Adult Mouse Anatomy (MA) [22] to return results annotated with either the term entered by the user or the parts of that structure. For example, a search for genes expressed in "eye" will return genes annotated with "eye", "retina", and "lens vesicle".
Developmental relationships: Searches for gene expression in an anatomical structure can be expanded by including structures linked by developmental relationships. The Xenbase gene expression database [23] provides an option to include successor and predecessor structures in search results. These relationships are provided by the Xenopus Anatomy Ontology (XAO) [24]. Developmental relationships also provide a way for users to navigate an atlas or database 
along developmental pathways. GUDMAP [25] is a database of gene expression in the mouse urogenital system. It employs the derives_from and differentiates_into relationships as links between the tissue summary pages with include gene expression data. This enables a user examining data annotated with "early distal tubule" to follow the differentiates_into relationship to data annotated with "renal distal tubule".

Structural relationships: Structural relationships allow a resource to present knowledge specific to an anatomical context. For example, the Virtual Fly Brain [26] provides an interface that uses the has_presynaptic_terminal_in and has_postsynaptic_terminal_in relationships for nerves in the Drosophila Anatomy Ontology [27]. For example, when viewing the medulla in the atlas, lists are generated for neurons with presynaptic and postsynaptic terminals the medulla. Producing the list of neurons requires two types of knowledge from the ontology: (a) which anatomical structures are part_of the medulla, (b) each neuron that has_presynaptic_terminal_in or has_postsynaptic_terminal_in those parts.

Ontologies also provide an opportunity to link resources to each other. For example, each anatomical term in the Zebrafish Anatomy Portal (ZFAP) [28] is linked to a page in ZFIN [29] that defines the term and provides ontological relationships.

\section{Spatial representation: $2 \mathrm{D}$ and 3D graphics}

The atlases and databases in this survey demonstrate several ways that spatial representation of anatomy can be enhanced in a web-based resource:

Graphics of developmental stages: The process of development can be studied only if it is represented in ways that are sufficiently rich in detail and reasonably standardized - a challenge as old as embryology itself [30]. Web-based atlases are able to represent spatial structure and time-based processes in way that traditional print-based resources cannot. For example, the Four-dimensional Ascidian Body Atlas (FABA) [31] defines stages for $C$. intestinalis with confocal image stacks and time-lapse movies, and the e-Mouse Atlas provides 3D reconstructions of embryos for many Theiler stages. Standardization of annotation for developmental stages is necessary for sharing data among laboratories, and atlases provide an easy way to access stage descriptions.

High-resolution histological sections: Glass histology slides have long been used for studying histology. Virtual slides are created by scanning and digitizing glass slides, and the experience of using a microscope is simulated through web applications that allow zooming and panning of the image. Virtual slides are provided by the Zebrafish Atlas [32] and e-Mouse Atlas [33].

Visual representation of ontological terms: Web-based resources provide an environment in which to link semantic and spatial representations of anatomical structures. For example, the Allen Developing Mouse Brain Atlas [34] and the Virtual Fly Brain [26] provide linked term-and-graphic windows that provide a view of both the ontology used and structures annotated with those terms. The Zebrafish Anatomy Portal (ZFAP) [28] provides a search function that takes a term from the Zebrafish Anatomy Ontology and returns planes of reconstructions from optical projection tomography (OPT) scans labeled with the term.

Correlating spatial data among specimens and experiments: For gene expression patterns to be useful, they must be annotated in a way that allows users to find genes that are expressed in regions of interest and to study co-expression patterns. Four methods are used to annotate expression patterns within the resources surveyed: (a) The first method is manual annotation of each specimen using terms from a controlled vocabulary or ontology. This method enables only text-based queries, and will be inaccurate where expression patterns do not correspond to the borders of defined anatomical regions. (b) The second approach relies on computational annotation and preserves the spatial nature of the data. In this approach, the expression pattern of each specimen is registered to a stage-matched standard volume through spatial warping enabling spatial queries to be performed across the dataset. This is used by the e-Mouse Atlas of Gene Expression (EMAGE) [19] (as described in [35]) and Allen Developing Mouse Brain Atlas [34] (as described in [36]). (c) A third approach, used by XenMARK [37], relies on a manual annotation process in which specimen expression patterns are drawn onto stage-specific schematic diagrams [38]. This method avoids the computational complexity of spatial warping, but allows spatial searches from the schematics. (d) A fourth approach is to compute similarity scores between pairs of images, instead of mapping to a stage-specific standard. This method is used by FlyExpress [39] on sets of 2D images of Drosophila embryos that are uniformly oriented and assayed under the same conditions [40].

\section{Patterns for interface design}

In order to document and generalize the approaches for conveying information about anatomy that are used in these atlas and databases, I compiled a set of patterns. Patterns are reusable solutions to design problems, and are of great interest in interface design [41]. The patterns I 
have identified focus on graphic representation, user interaction, and navigation.

From the anatomical atlases I identified a total of 23 design patterns, shown in Figs. 3, 4, 5 and 6. These patterns provide methods for displaying graphics, integrating semantic and spatial representations, and organizing atlas information. They are grouped into eight categories:

- Displaying 2D graphics

- Displaying sectional graphics

- Displaying 3D graphics

- Labeling graphics

- Presenting topic-focused information

- Defining anatomical terms

- Organizing information about developmental stages

- Describing development using graphical methods

Each pattern has a title, description, examples of use, and simple pictorial representation. For example, one pattern in the category of "Displaying 2D graphics" is "Overview plus detail." This pattern pairs a small overview graphic with a large zoomable graphic. A box on the small graphic indicates the region shown in the zoomable graphic. This pattern can be used when high-resolutions graphics are available and it is important to allow the user to zoom into details. This pattern is used within the e-Mouse Atlas [33], Virtual Fly Brain [26], WormAtlas (SlidableWorm) [42], and Zebrafish Atlas [32].

From the gene expression atlases and databases I identified 13 patterns that provide methods for querying databases to find genes expressed in anatomical structures and display the results. These patterns are shown in Figs. 7 and 8 , and are grouped into four categories:

- Providing textual methods for querying a gene expression database

- Providing graphical methods for querying a gene expression database

- Displaying query results from a gene expression database

- Explaining anatomical annotations in a query result item

A few of the patterns that I present here have been previously identified in other pattern collections. In these cases I have retained the names given by previous authors (for example, "Overview plus detail", "Autocompletion", and "Thumbnail grid") [41].

\section{Discussion}

This collection of design patterns can be used as a catalyst for conversations between biologists and software developers. Because they provide a user-focused perspective, they can support discussions of methods for exploring and retrieving anatomically-based information and can serve as building blocks for interface specifications.

The patterns also help to clarify how interface functionality is constrained by the investment in semantic and spatial standardization. For example, one of the most intuitive ways to query a gene expression pattern database is by specifying a point or region on a standardized image, but this requires that the expression data have been mapped to a spatial standard.

This work documents the variety of ways anatomical information has been communicated in online atlases and databases. Part of this variability is due to differences in the types of data available, purposes of the resources, and the characteristics of the organism. But it also reflects the large number of design solutions that are possible. Because this survey did not include resources presented as downloadable software, there are likely to be additional patterns for representing anatomy.

\section{Using the patterns to support user needs}

When applied to developing or expanding a particular online resource, this work should be considered in the context of two important considerations: "What are the information needs of the users?" and "What information assets are available to use in building the resource?" The patterns act as intermediaries between the users' questions and the information assets. Figure 9 provides a scenario that uses ten of the patterns in an imagined resource. This resource provides an anatomical atlas and gene expression database, and uses information assets including an ontology (serving as the semantic standard), spatial standards, a graphics collection, and gene expression data. In this scenario, user needs include obtaining information about the meaning of anatomical terms and finding data related to development of a particular anatomical structure.

\section{Designing for new types of data}

Looking to the future, standardized spatial representations will be key to communicating and integrating new types of data. Emerging techniques for "spatially resolved omics" [43] provide high-throughput measurements of gene expressions while preserving detailed spatial information. For example, microtomy sequencing provides gene expression data from individual cryosections of a specimen. Recent work with zebrafish embryos extends this approach by analyzing data from embryos sectioned along orthogonal body axes using image reconstruction algorithms to produce 3D expression patterns-a technique called RNA tomography (or tomo-seq) [44]. 


\section{Displaying 2D graphics}
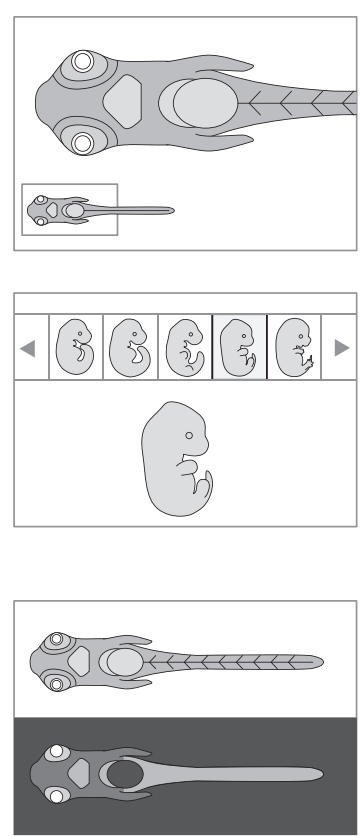

\section{Graphics comparison panels}

Similar graphics are displayed side-by-side.

Use to facilitate comparison of graphicss, such as the same subject represented with different imaging modalities or specimens of a wild type and mutant phenotype.

\section{Carousel}

A scrolling strip of thumbnail graphics provides a method of selecting a graphic or set of information to view.

items that are easily identified by thumbnail graphics when screen space is limited.
Use when high-resolution images are available and it is important to allow the user to zoom in to examine details.

Examples of atlases using this pattern are the e-Mouse Atlas, Virtual Fly Brain, WormAtlas (SlidableWorm), and Zebrafish Atlas.
This patterns works well for sequences of items, such as stages of development or histological sections.

Examples of atlases using this pattern are the Allen Developing Mouse Brain Reference Atlas, e-Mouse Atlas, and ZFAP.

This pattern is used in the "Sample comparisons" section of the Zebrafish Atlas.

\section{Displaying sectional graphics}
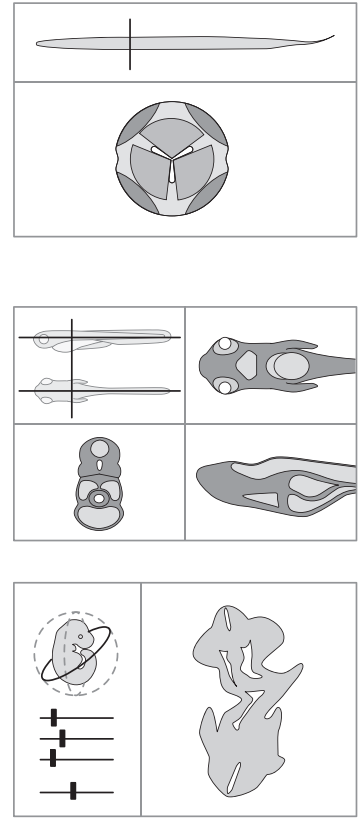

\section{Single-plane viewer}

A graphic of an section is paired with a graphic showing the location of the section within the body. Sections are selected by either clicking on the body graphic or using "forward" and "back" buttons.

Use to display a series of sections along a single axis.

\section{Orthogonal-plane viewer}

Orthogonal planes within a body are presented with reference graphics showing two external views of the body. Sections are selected by clicking points on the reference graphics.

\section{Arbitrary-plane viewer}

A single section at any plane from a 3D reconstruction is displayed. The pitch, yaw, and roll of the plane, as well as the distance of the plane on the major axis of the body, are set using sliders. A reference graphic of the body displays the orientation of the plane.
This pattern can be applied to displays of either physical sections (histological sections, transmission electron micrographs) or virtual sections (such as confocal planes).

Examples of atlases using this pattern are the Allen Developing Mouse Brain Reference Atlas, e-Mouse Atlas (Histological sections), FABA, and FishNet.

Use to display planes within a 3D scan reconstruction.

This pattern is used in the ZFAP atlas to present optical projection tomography reconstructions.

Use to display planes within a 3D scan reconstruction in cases when viewing orthogonal planes is insufficient or screen space is limited.

This pattern is used in the e-Mouse Atlas (3D reconstructions) and Virtual Fly Brain.

Fig. 3 Interface design patterns for displaying 2D graphics and sectional graphics

The detailed spatial data produced by large-scale gene expression studies are unlikely to correspond to traditionally defined regions of anatomy. Therefore, standardized spatial representations of model organisms will need to serve as a mediator between the data collected by laboratories and the users of community databases. In this 


\section{Displaying 3D graphics}
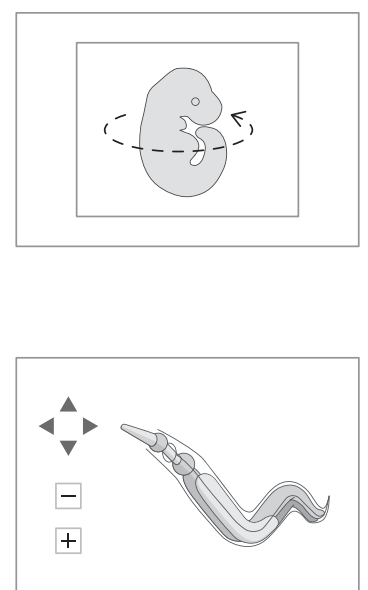

\section{D rotation window}

A 3D representation can be rotated by the user. Rotation is commonly constrained to a single axis.

The view is controlled by either playing a movie sequence or directly controlling orientation with the mouse.

This pattern has been used with both 3D volume and surface models.

\section{D model viewer}

A viewer for a 3D surface model that allows the user to hide and show individual components of the model and to rotate the model.
3D scan reconstructions are presented in the e-Mouse Atlas, FABA, FishFace, Interactive Atlas of Zebrafish Vascular Anatomy, and ZFAP. 3D surface models are displayed using WebGL in the Virtual Fly Brain (neuron models) and by using a series of images captured at $2^{\circ}$ intervals in Flygut.

This pattern is also used to show regions of gene expression in the EMBRYS expression atlas and Allen Developing Mouse Brain Atlas (ISH Data).

OpenWorm Browser uses this pattern.

\section{Labeling graphics}
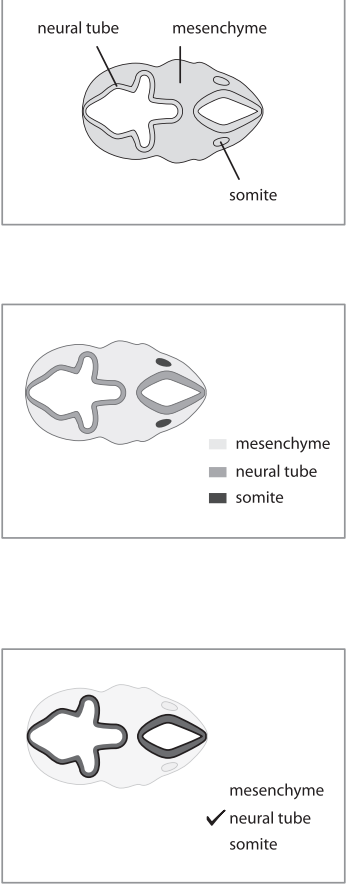

\section{Direct labeling}

Text labels are spatially associated with regions within a graphic. Labels may be placed within the regions they label or associated with a region through use of leader lines or arrows.
An option to show/hide all labels may be useful to reduce visual clutter. Alternatively, only labels for the currently selected region may be shown.

If borders of the labeled regions are not obvious, consider combining this pattern with Color-coded overlay, as used in the Allen Developing Mouse Brain Reference Atlas and WormAtlas (SlidableWorm).

\section{Color-coded overlay}

Color is used to labeled regions of a graphic. A color key associates the color with a text label.

Use when fewer than ten types of structures are to be labeled. For a greater number of regions, combine this pattern with Direct labeling or use interactivity to associate a text label with a colored region.

\section{Spotlight}

A single structure within a graphic is highlighted by fading, shadowing, or hiding all other regions.
Consider allowing the user to show/hide the color overlays for individual regions, as implemented in the Virtual Fly Brain and section viewers for the e-Mouse Atlas using the Linked term-and-graphic windows pattern.

Retaining visibility of the graphic through the color overlay may be important. WormAtlas

(SlidableWorm) provides options for opaque and transparent color overlays.

The Medaka Blood Vessel Atlas (Adult) uses this pattern to interactively associate terms in a list with regions of an adjacent graphic.

OpenWorm Browser also uses this pattern. When a component of the 3D surface model is selected, other components fade and a text label is displayed next to the component.

Fig. 4 Interface design patterns for displaying 3D graphics and labeling graphics

scenario, investigators will not annotate their data with semantic annotations. Rather, they will map their data to standard spatial representations. The role of semantic representations will be to serve as references to regions of the models and logical links between models at different stages or at different spatial scales. This will integrate disparate data at the level of spatial representation, while preserving the usefulness of semantic representations for filtering, searching, and browsing data.

\section{Conclusions}

This work highlights issues important for the continued evolution of online resources for developmental biology. If resources are to be effective in helping researchers to locate 


\section{Presenting topic-focused information}
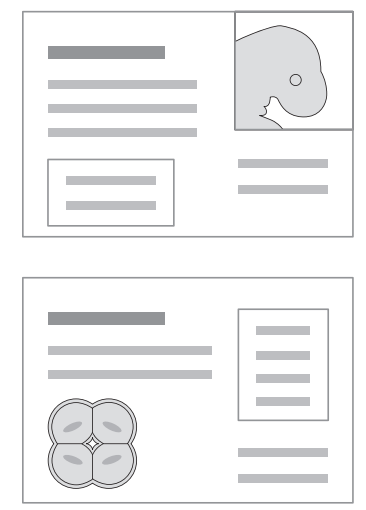

\section{Structure-focused page}

A page that gathers information relevant to an anatomical structure.

Use when information in a variety of forms (such as narrative descriptions, graphics, and anatomical terms) are to be viewed together.
Atlases using this pattern include Flygut, FishFace, and WormAtlas (Individual Neurons).

ZFIN and GUDMAP provide structure-focused pages based the ontologies they use.

\section{Stage-focused page}

A page that gathers information relevant to a single developmental stage.

Use a series of stage-focused pages to provide detailed information about each stage.
Atlases using this pattern include ANISEED,

FABA, and Medaka Blood Vessel Atlas.

\section{Defining anatomical terms}
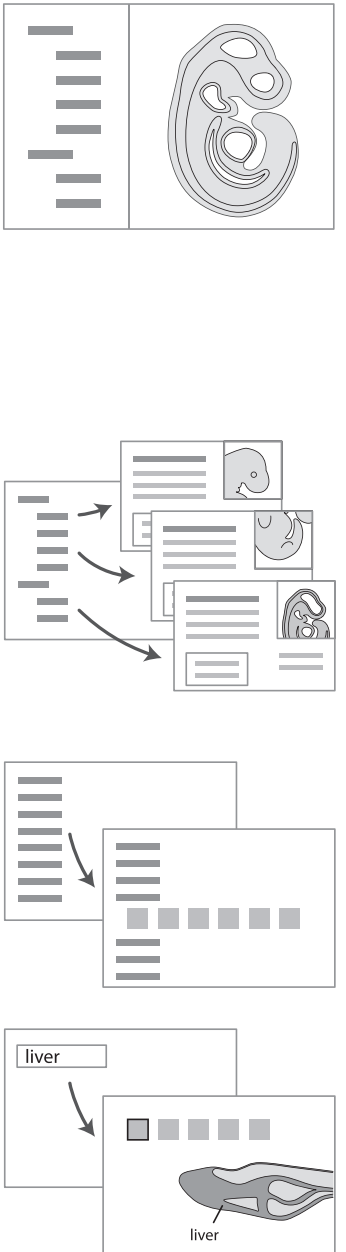

\section{Linked term-and-graphic windows}

A panel with anatomical terms is displayed next to a graphic. Clicking on a term highlights the corresponding region of the graphic. In some implementations, links also exist in the opposite direction (so that selecting a region of the graphic highlights the corresponding term).

Use when a large number of anatomical terms are associated with a single graphic.

\section{Terms as index for structure-focused pages}

The user is presented with a collection of anatomical terms. Selecting a term opens a Structure-focused page.

Use when structure-focused pages are available for each term.

\section{Term list with information inlays}

The user is presented with a list of anatomical terms. Selecting a term reveals relevant graphics, text, or links beneath the term.

Use when only a small amount of information needs to be associated with a term.

\section{Term search for labeled graphics}

The user enters an anatomical term in a search box and is provided with a set of graphics showing the structure.

Use to provide a visual representation of anatomical structures when annotated graphics are available.
This pattern is implemented in a single direction within the e-Mouse Atlas (Interactive Anatomy Browser) and Virtual Fly Brain. It is implemented in both directions within the Allen Developing Mouse Brain Reference Atlas. Each of these atlases combines this pattern with one of the patterns for displaying sectional graphics.

An complication arises if a term is selected that refers to an anatomical structure not visible in the section currently displayed. The Allen Developing Mouse Brain Reference Atlas addresses this issue by switching the graphic to a nearby section that contains that anatomical structure.

This pattern can be implemented in several ways: linking to a separate page, updating an adjacent panel of information while retaining a view of the list or hierarchy, or using a pop-up window.

Atlases using this pattern include ANISEED, WormAtlas (Individual Neurons) and Zebrafish Atlas.

The Medaka Blood Vessel Atlas (Adult) uses this pattern to display thumbnail graphics that serve as links to full-size graphics.

Note: The basic pattern is commonly known as "List inlay".

Could be combined with additional information, such as a textual definition and relationships from an ontology.

ZFAP combines this pattern with the Orthogonal plane viewer. The Zebrafish Atlas uses this patterns to show histological sections.

Fig. 5 Interface design patterns for presenting topic-focused information and defining anatomical terms 


\section{Organizing information about developmental stages}
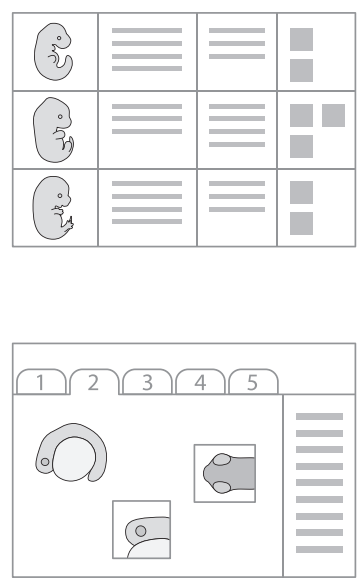

\section{Table of stage information}

A table is used to summarize information about develomental stages, with each row corresponding to a stage.

Use to present brief, structured information about stages and to encourage comparison among stages. May include links to stage-focused pages with detailed information.

\section{Dual indexing by stage and structure}

A set of stage-specific pages are displayed next to a collection of anatomical terms. Selecting a term highlights the tabs of each stage for which that term is relevant, switches to the page of a relevant stage if needed, and highlights information about that anatomical structure on each page.
This pattern is used within the e-Mouse Atlas, FABA, Interactive Atlas of Zebrafish Anatomy, and Zebrafish Atlas.

\section{Describing development using graphical methods}
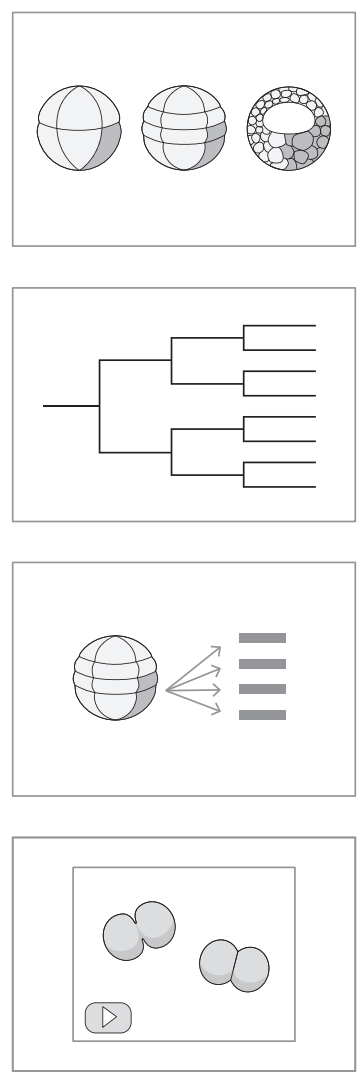

\section{Sequence of developmental graphics}

A sequence of graphics showing development of a region within an embryo.
Use when it is equally important to allow the user to access information by stage or by structure, and the amount of information relevant to a stage can be displayed within a single page.

This pattern is used within the Medaka Blood Vessel Atlas (Developmental).

\section{Lineage diagram}

A diagram showing the lineage of cells or regions within an embryo.
Use to describe morphological changes in an embryo.

Xenbase uses this pattern to describe four early stages of embryos.

\section{Fate map}

A graphical depiction of a region of an early embryo paired with a list of anatomical structures within advanced embryos or adults that arise from the region.
Use to describe development and differentiation throughout an entire embryo.

FABA and ANISEED both provide lineage diagrams.

\section{Time-lapse movie of development}

A movie showing the development of live embryos.
Use when a graphic of an early embryo communicates more clearly than naming the region of the embryo.

Xenbase provides fate maps for the 32-cell stage embryo.

Fig. 6 Interface design patterns for organizing information about developmental stages and describing development using graphical methods

data relevant to their questions and to generate hypotheses, they must provide a structure that allows researchers to navigate within the space-scale-time matrix depicted in Fig. 1, as well as to explore homologous structures across different species. This next generation of resources-perhaps better described as web portals-will provide access to not only information from different laboratories stored within a single repository, but to
Use to show the appearance of live cells and as a way to allow the user to select a period of development to examine in detail.

FABA provides time-lapse movies of developing Ciona from single cells through late tailbud stage. 


\section{Providing textual methods for querying a gene expression database}
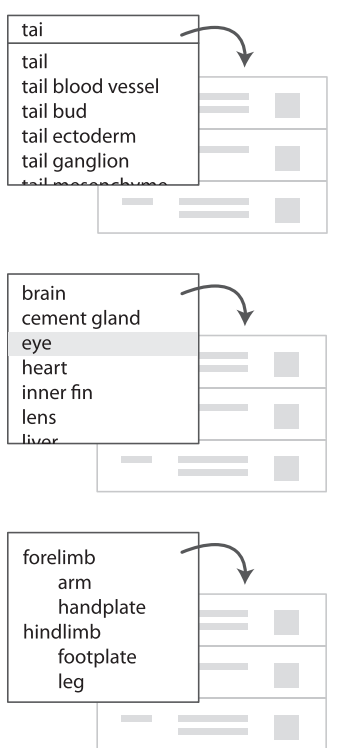

\section{Autocompletion}

Once the user begins typing characters, a list of terms is suggested based on a controlled vocabulary or ontology.
Use when a large number of terms have been used to annotate data and the user will be familiar with the terms.

This patterns is used in ANISEED, EMAGE, FlyBase (QuickSearch), GXD, GUDMAP, Xenbase, and ZFIN

\section{Query terms in a list}

The user selects an anatomical structure from terms arranged as a list.

Use when only a small number of terms have been used to annotate the data.
Examples of this pattern appear in Expression Patterns for $C$. elegans promoter::GFP fusions, FlyExpress, GEMS, MEPD, Xenbase, and XenMARK expression patterns.

\section{Providing graphical methods for querying a gene expression database}
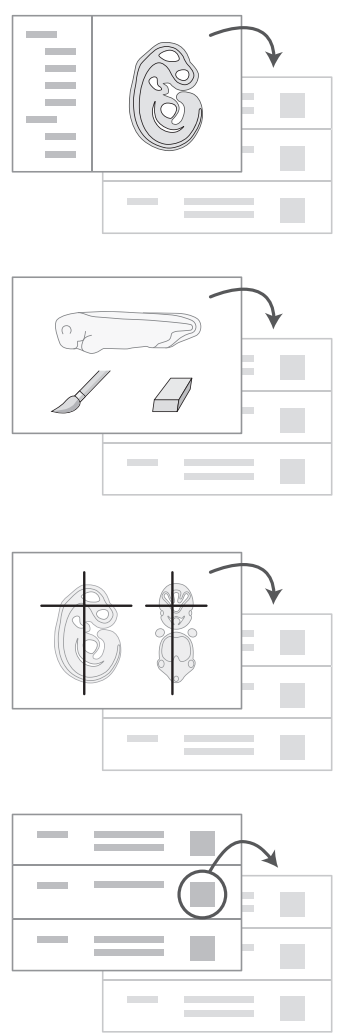

Query from a structure in an anatomical atlas

The user selects a structure from within an anatomical atlas and then executes a query to a gene expression database.
It is helpful to show the number of items annotated with each term so that the user can avoid querying for terms not used in annotation.

This pattern is used in Allen Developing Mouse Brain Atlas (ISH Data, Annotation Search),

Eurexpress, FlyBase (QueryBuilder), GenePaint, GEISHA, and GUDMAP. annotating expression patterns and to guide users to a term with the level of specificity they desire.

Use when terms have been standardized between an atlas and gene expression database.

The e-Mouse Atlas can be used to initiate queries to EMAGE and GXD.

\section{Paint region for query on a reference graphic}

The user first selects a standardized 2D graphic for a developmental stage and then draws on the graphic to indicate a region of expression for the query.

\section{Identify point for query using crosshairs}

The user first selects a set of standardized 2D graphics for a developmental stage and then moves the crosshairs to select a point of interest for the query.
Use when expression data have been mapped to $2 \mathrm{D}$ or $3 \mathrm{D}$ standard models. The density of expression data in different regions can be encoded using a color intensity "heatmap" on the reference graphic.

This method of querying is offered by EMAGE, FlyExpress, and XenMARK expression patterns.

Use when expression data have been mapped to 3D standard models.

The Allen Developing Mouse Brain Atlas (AGEA) uses this pattern.

\section{Find expression patterns similar to a query result}

Once the user is presented with a table of query results, a subsequent query can be executed using one of the result items.
This pattern can be used when the expression data has been mapped to 2D or 3D standard models. This method of querying is offered by EMAGE and XenMARK,

BDGP and Eurexpress have a similar function, but rely on term-based annotations to find similar patterns. FlyExpress using similarity scores between pairs of graphics.

Fig. 7 Interface design patterns for textual and graphical methods of querying a gene expression database 


\section{Displaying query results from a gene expression database}
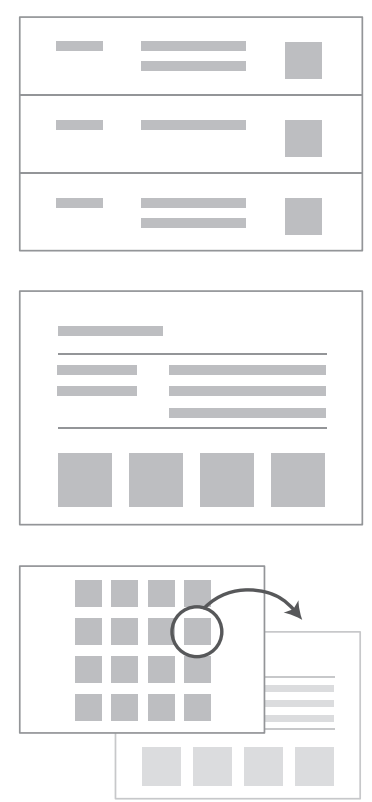

\section{Thumbnail grid of graphics}

A page that displays an array of graphics and links to a gene sumary page.

Use when the graphic associated with a gene expression assay can quickly communicate anatomical location of the expression.

\section{Explaining anatomical annotations in a query result item}
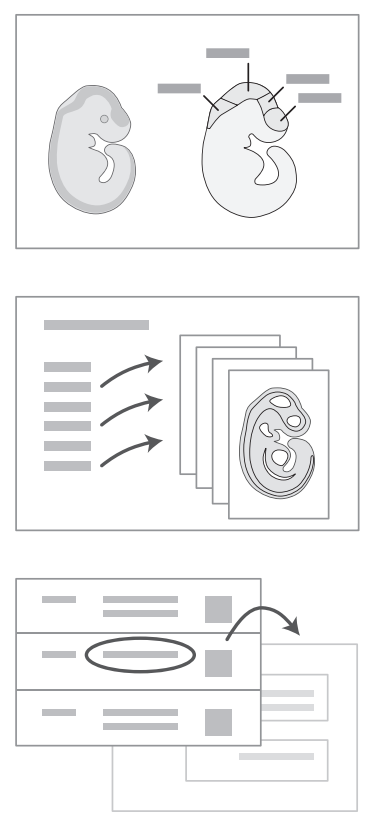

\section{Gene expression graphic paired with} annotated atlas graphic

A graphic of an embryo showing regions of gene expression is displayed in the same window as an annotated atlas graphic (either a micrograph or illustration).
Use to graphically define anatomical terms relevant to a particular pattern of gene expression. This pattern is used in EMBRYS and the GENSAT "Anatomy showcase".
Use to provide a text-based summary of query results for the user to scan. To provide additional information about an item, provide a link to a Gene summary page.

This pattern is used by all the gene expression databases in this survey.

May be supplemented with pages that provide details of the results for a gene from a particular assay.

This pattern is used by many gene expression databases, including ANISEED, GEISHA, and GUDMAP

This pattern is used by GENSAT for the showcase pages and within the EMAGE "Similar patterns" tool.

\section{Anatomical annotations linked to histological sections}

For each anatomical structure annotated as a site of expression for a gene, a link to a relevant histological section is provided.
Use to communicate to the user the evidence for expression in the structure.

This pattern is used by Eurexpress and GenePaint.

\section{Anatomical annotations linked to term definitions}

Anatomical terms in a Table of query results are linked to the definition from the ontology.
Use to communicate the standardized definition of this anatomical term, as well synonyms, the term ID, or other information of interest.

The databases using this pattern include WormAtlas (WormMine) and Flybase.

Fig. 8 Interface design patterns for displaying query results from a gene expression database and explaining anatomical annotations

information distributed across different repositories. These web portals (and perhaps networks of interlinked web portals) will rely on tightly integrated semantic and spatial representation, using anatomy as a framework for data integration, organization and navigation.
As model organism communities move toward the goal of building a comprehensive understanding of development, the role of these web portals is crucial. They will serve both to document collective knowledge from previous work and to provide the infrastructure that enables 


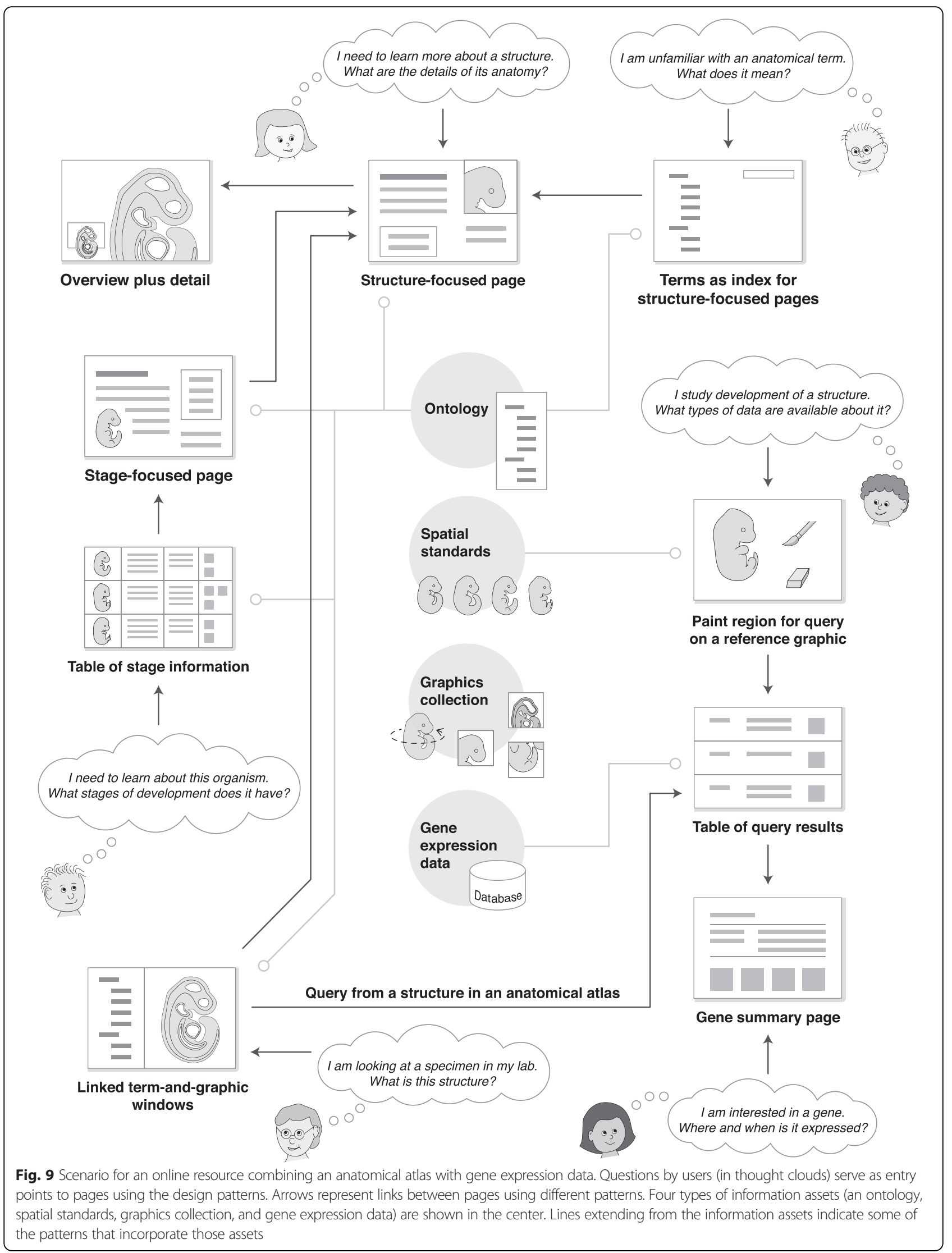


future work. Achieving this vision will require not only advances in web and imaging technology, but careful consideration of semantic and spatial representation and research to design usable and intuitive interfaces. In order for these tools to meet the needs of biologists, biologists must partner with computer science, informatics, and design researchers.

\section{Methods}

The atlases and databases surveyed in this work were identified through keyword searches of the Science Direct, Scopus, and PubMed databases. The keywords used were atlas or database in combination with Arbacia, Caenorhabditis elegans, chick, chicken, Ciona, Danio rerio, Drosophila, fly, frog, Gallus gallus, medaka, mouse, Mus musculus, nematode, Oryzias latipes, rat, Rattus norvegicus, sea squirt, sea urchin, Strongylocentrotus, Xenopus, or zebrafish. Several additional atlases and databases were identified based on URL links within these resources. Keyword searches were performed on 26 July 2014 and 9 Oct 2015.

Resources included in this survey are (a) described in a peer-reviewed journal article, (b) publicly available, (c) delivered on the web without requiring download, and (d) in English. In addition, a resource must have been available on at least one of the dates of testing (26 July 2014, 4 Aug 2014, 6 Sept 2014, and 9 Oct 2015). If a resources consists of both online material and downloadable material, only the online material was included in this survey. Two resources became unavailable during the course of this project (EMBRYS and GEMS). These are included in the survey, but their unavailability is noted with their URLs in Table 3.

Resources were excluded if they are primarily (a) databases of microarray data, (b) collections of figures from journal articles, (c) collections of graphics or movies with little or no annotation of anatomical structures, or (d) textbook-like resources with limited navigation structure. This work is limited to model organisms, and therefore resources for human anatomy and development are excluded.

All resources were viewed using operating system Mac OSX 10.9.5 with Java 1.8.0 and the Firefox 41.0 browser. Components provided as self-signed Java applications were excluded from this survey due to security risks.

\section{Ethics approval and consent to participate}

Not applicable.

\section{Consent for publication}

Not applicable.

\section{Availability of data and material}

This study did not generate datasets.

\section{Abbreviations}

2D: two dimensional; 3D: three dimensional; DIC: differential inference contrast; OPT: optical projection tomography; ssTEM: serial section transmission electron micrograph; TEM: transmission electron micrograph.

\section{Competing interests}

The author declares she has no competing interests.

Authors' contributions

All work was performed by M.C.

Funding

The author received no funding for this work.

Received: 11 January 2016 Accepted: 9 May 2016

Published online: 21 May 2016

References

1. de Boer BA, Ruijter JM, Voorbraak FPJM, Moorman AFM. More than a decade of developmental gene expression atlases: where are we now? Nucleic Acids Res. 2009;37:7349-59.

2. Geffers L, Herrmann B, Eichele G. Web-based digital gene expression atlases for the mouse. Mamm Genome. 2012;23:525-38.

3. Baldock R, Bard J, Kaufman M, Davidson D. What's New? A real mouse for your computer. Bioessays. 1992;14:501-2.

4. Bult CJ. Data integration standards in model organisms: from genotype to phenotype in the laboratory mouse. TARGETS. 2002;1:163-8.

5. Leonilli S, Ankeny RA. Re-thinking organisms: the impact of databases on model organism biology. Stud Hist Phil Biol Biomed Sci. 2012;43:29-36.

6. Ashburner M, Ball CA, Blake JA, Botstein D, Butler H, Cherry M, et al. Gene Ontology: tool for the unification of biology. Nat Genet. 2000;25:25-9.

7. Hill DP, Berardini TZ, Howe DG, Van Auken KM. Representing ontogeny through ontology: a developmental biologist's guide to the gene ontology. Mol Reprod Dev. 2010;77:314-29.

8. Lee W-P, Tzou W-S. Computational methods for discovering gene networks from expression data. Brief Bioinform. 2009;10:408-23.

9. Boline J. Digital atlases as a framework for data sharing. Front Neurosci. 2008;2:100-7.

10. Husz ZL, Burton N, Hill B, Milyaev N, Baldock RA. Web tools for large-scale 3D biological images and atlases. BMC Bioinformatics. 2012;13:122.

11. Lee D, Ruffins S, Ng Q, Sane N, Anderson S, Toga A. MBAT: a scalable informatics system for unifying digital atlasing workflows. BMC Bioinformatics. 2010;11:608.

12. Bakker R, Tiesinga P, Kötter R. The Scalable Brain Atlas: instant web-based access to public brain atlases and related content. Neuroinformatics. 2015; 13:353-66.

13. Fowlkes CC, Hendriks CLL, Keränen SVE, Weber GH, Rübel O, Huang M-Y, et al. A quantitative spatiotemporal atlas of gene expression in the Drosophila blastoderm. Cell. 2008;133:364-74.

14. Lee E-F, Boline J, Toga AW. A high-resolution anatomical framework of the neonatal mouse brain for managing gene expression data. Front Neuroinform. 2007;1:6.

15. Meyer M, Munzner T, DePace A, Pfister H. MulteeSum: a tool for comparative spatial and temporal gene expression data. IEEE Trans Vis Comput Graph. 2010;16:908-17.

16. Han L, van Hemert Jl, Baldock RA. Automatically identifying and annotating mouse embryo gene expression patterns. Bioinformatics. 2011;27:1101-7.

17. Boehm B, Rautschka M, Quintana L, Raspopovic J, Jan Z, Sharpe J. A landmark-free morphometric staging system for the mouse limb bud. Development. 2011;138:1227-34

18. Wong M, van Eede MC, Spring S, Jevtic S, Boughner JC, Lerch JP, et al. 4D atlas of the mouse embryo for precise morphological staging. Development. 2015;142:3583-91.

19. EMAGE. http://www.emouseatlas.org/emage/home.php. Accessed 25 Mar 2015.

20. Jackson Laboratory. Mouse Gene Expression Database. http://www. informatics.jax.org/gxd. Accessed 25 Mar 2015.

21. Hayamizu TF, Wicks MN, Davidson DR, Burger A, Ringwald M, Baldock RA. EMAP/EMAPA ontology of mouse developmental anatomy: 2013 update. J Biomed Semantics. 2013;4:15. 
22. Hayamizu TF, Mangan M, Corradi JP, Kadin JA, Ringwald M. The Adult Mouse Anatomical Dictionary: a tool for annotating and integrating data. Genome Biol. 2005;6:R:29.

23. Xenbase. http://www.xenbase.org/entry. Accessed 25 Mar 2015.

24. Segerdell E, Ponferrada VG, James-Zorn C, Burns KA, Fortriede JD, Dahdul WM, et al. Enhanced XAO: the ontology of Xenopus anatomy and development underpins more accurate annotation of gene expression and queries on Xenbase. J Biomed Semantics. 2013;4:31.

25. GUDMAP Consortium. GUDMAP: Genitourinary Development Molecular Anatomy Project. http://www.gudmap.org. Accessed 25 Mar 2015.

26. Armstrong D, Milyaev N, Osumi-Sutherland D, Reeve S, Costa M, O'Kane C, et al. Virtual Fly Brain. http://www.virtualflybrain.org. Accessed 25 Mar 2015

27. Costa M, Reeve S, Grumbling G, Osumi-Sutherland D. The Drosophila anatomy ontology. J Biomed Semantics. 2013;4:32.

28. Salgado D, Currie P, Marcelle C, Bryson-Richardons R. ZebraFish Anatomy Portal (ZFAP). http://zebrafish.anatomyportal.org. Accessed 25 Mar 2015.

29. ZFIN: The Zebrafish Model Organism Database. http://zfin.org. Accessed 25 Mar 2015

30. Hopwood N. A history of normal plates, tables and stages in vertebrate embryology. Int J Dev Biol. 2007;51:1-26.

31. FABA: Four-dimensional Ascidian Body Atlas. http://tunicate-portal.org/faba/ 1.4/top.html. Accessed 25 Mar 2015.

32. Jake Gittlen Cancer Research Foundation. Zebrafish Atlas. http://bio-atlas. psu.edu/zf. Accessed 25 Mar 2015.

33. EMAP: The e-Mouse Atlas Project. http://www.emouseatlas.org/emap/home. html. Accessed 25 Mar 2015

34. Allen Institute for Brain Science. Allen Developing Mouse Brain Atlas. http:// developingmouse.brain-map.org. Accessed 25 Mar 2015.

35. Hill B, Baldock RA. Constrained distance transforms for spatial atlas registration. BMC Bioinformatics. 2015;16:90.

36. Lein ES, Hawrylycz MJ, Ao N, Ayres M, Bensinger A, Bernard A, et al. Genomewide atlas of gene expression in the adult mouse brain. Nature. 2007;445:168-76.

37. XenMARK. http://genomics.crick.ac.uk/apps/XenMARK. Accessed 25 Mar 2015.

38. Gilchrist MJ, Christensen MB, Bronchain O, Brunet F, Chesneau A, Fenger U, et al. Database of queryable gene expression patterns for Xenopus. Dev Dyn. 2009;238:1379-88.

39. FlyExpress. http://www.flyexpress.net. Accessed 25 Mar 2015.

40. Konikoff CE, Karr TL, McCutchan M, Newfeld SJ, Kumar S. Comparison of embryonic expression within multigene families using the FlyExpress discovery platform reveals more spatial than temporal divergence. Dev Dyn. 2012;241:150-60.

41. Tidwell J. Designing interfaces. second edition. O'Reilly Media; 2011.

42. Altun ZF, Herndon LA, Crocker C, Lints R, Hall DH. WormAtlas. http://wormatlas.org. Accessed 25 Mar 2015.

43. Crosetto N, Bienko M, van Oudenaarden A. Spatially resolved transcriptomics and beyond. Nat Rev Genet. 2014;16:57-66.

44. Junker JP, Noël ES, Guryev V, Peterson KA, Shah G, Huisken J, et al. Genome-wide RNA tomography in the zebrafish embryo. Cell. 2014;159:662-75.

45. The SG, Worm T. C. elegans, Worm Atlas, Worm Image and the Slidable Worm: from the webpage to the classroom. Microsc Microanal. 2007;13:208-9.

46. Yook K, Harris TW, Bieri T, Cabunoc A, Chan J, Chen WJ, et al. WormBase 2012: more genomes, more data, new website. Nucleic Acids Res. 2012;40:D735-41.

47. Brozovic M, Martin C, Dantec C, Dauga D, Mendez M, Simion P, et al. ANISEED 2015: a digital framework for the comparative developmental biology of ascidians. Nucleic Acids Res. 2016;44:D808-18.

48. Tassy O, Dauga D, Daian F, Sobral D, Robin F, Khoueiry P, et al. The ANISEED database: digital representation, formalization, and elucidation of a chordate developmental program. Genome Res. 2010;20:1459-68.

49. Hotta K, Mitsuhara K, Takahashi H, Inaba K, Oka K, Gojobori T, et al. A webbased interactive developmental table for the ascidian Ciona intestinalis, including 3D real-image embryo reconstructions: I. From fertilized egg to hatching larva. Dev Dyn. 2007;236:1790-805.

50. Buchon N, Osman D, David FPA, Yu Fang H, Boquete J-P, Deplancke B, et al. Morphological and molecular characterization of adult midgut compartmentalization in Drosophila. Cell Rep. 2013;3:1725-38.

51. Milyaev N, Osumi-Sutherland D, Reeve S, Burton N, Baldock RA, Armstrong JD. The Virtual Fly Brain browser and query interface. Bioinformatics. 2012;28:411-5.

52. Isogai S, Fujita M. Anatomical atlas of blood vascular system of medaka. In: Naruse K, Tanaka M, Takeda H, editors. Medaka: A model organism for organogenesis, human disease, and evolution. Tokyo: Springer Japan; 2011. p. 95-109.

53. Fujita M, Isogai S, Kudo A. Vascular anatomy of the developing medaka, Oryzias latipes: a complementary fish model for cardiovascular research on vertebrates. Dev Dyn. 2006;235:734-46.

54. Sunkin SM, Ng L, Lau C, Dolbeare T, Gilbert TL, Thompson CL, et al. Allen Brain Atlas: an integrated spatio-temporal portal for exploring the central nervous system. Nucleic Acids Res. 2013;41:D996-1008.

55. Allen Institute for Brain Science. Technical white paper: Reference atlases for the Allen Developing Mouse Brain Atlas. 2010. http://developingmouse. brain-map.org/docs/ReferenceAtlas.pdf

56. Armit C, Richardson L, Hill B, Yang Y, Baldock RA. eMouseAtlas informatics: embryo atlas and gene expression database. Mamm Genome. 2015;26:431-40.

57. Richardson L, Graham L, Moss J, Burton N, Roochun Y, Armit C, et al. Developing the eHistology Atlas. Database. 2015;2015:bav105.

58. Armit C, Venkataraman S, Richardson L, Stevenson P, Moss J, Graham L, et al. eMouseAtlas, EMAGE, and the spatial dimension of the transcriptome. Mamm Genome. 2012;23:514-24.

59. Baldock RA, Bard JBL, Burger A, Burton N, Christiansen J, Feng G, et al. EMAP and EMAGE: a framework for understanding spatially organized data. Neuroinformatics. 2003:1:309-26.

60. Davidson D, Bard J, Kaufman M, Baldock R. The Mouse Atlas Database: a community resource for mouse development. Trends Genet. 2001;17:49-51.

61. Baldock RA, Dubreuil C, Hill B, Davidson D. The Edinburgh Mouse Atlas: basic structure and informatics. In: Letovsky S, editor. Bioinformatics: Databases and Systems. Boston: Kluwer Academic Publishers; 1999.

62. Eames B, DeLaurier A, Ullmann B, Huycke TR, Nichols JT, Dowd J, et al. FishFace: interactive atlas of zebrafish craniofacial development at cellular resolution. BMC Dev Biol. 2013;13:23.

63. Bryson-Richardson RJ, Berger S, Schilling TF, Hall TE, Cole NJ, Gibson AJ, et al. FishNet: an online database of zebrafish anatomy. BMC Biol. 2007;5:34.

64. Isogai S, Horiguchi M, Weinstein BM. The vascular anatomy of the developing zebrafish: an atlas of embryonic and early larval development. Dev Biol. 2001;230:278-301.

65. Salgado D, Marcelle C, Currie PD, Bryson-Richardson RJ. The Zebrafish Anatomy Portal: a novel integrated resource to facilitate zebrafish research. Dev Biol. 2012;372:1-4.

66. Cheng KC. A life-span atlas for the zebrafish. Zebrafish. 2004;1:69.

67. Cubbage CC, Mabee PM. Development of the cranium and paired fins in the zebrafish Danio rerio (Ostariophysi, Cyprinidae). J Morphol. 1996;229:121-60.

68. Ito K, Shinomiya K, Ito M, Armstrong JD, Boyan G, Hartenstein V, et al. A systematic nomenclature for the insect brain. Neuron. 2014;81:755-65.

69. Hunt-Newbury R, Viveiros R, Johnsen R, Mah A, Anastas D, Fang L, et al. High-throughput in vivo analysis of gene expression in Caenorhabditis elegans. PLoS Biol. 2007;5:e237.

70. Harris TW, Baran J, Bieri T, Cabunoc A, Chan J, Chen WJ, et al. WormBase 2014: new views of curated biology. Nucleic Acids Res. 2014;42:D789-93.

71. Antin PB, Yatskievych TA, Davey S, Darnell DK. GEISHA: an evolving gene expression resource for the chicken embryo. Nucleic Acids Res. 2014;42:D933-7.

72. Darnell DK, Kaur S, Stanislaw S, Davey S, Konieczka JH, Yatskievych TA, et al. GEISHA: an in situ hybridization gene expression resource for the chicken embryo. Cytogenet Genome Res. 2007;117:30-5.

73. Bell GW, Yatskievych TA, Antin PB. GEISHA, a whole-mount in situ hybridization gene expression screen in chicken embryos. Dev Dyn. 2004;229:677-87.

74. Hammonds AS, Bristow CA, Fisher WW, Weiszmann R, Wu S, Hartenstein V, et al. Spatial expression of transcription factors in Drosophila embryonic organ development. Genome Biol. 2013;14:R140.

75. Tomancak P, Berman BP, Beaton A, Weiszmann R, Kwan E, Hartenstein V, et al. Global analysis of patterns of gene expression during Drosophila embryogenesis. Genome Biol. 2007;8:R145.

76. Tomancak P, Beaton A, Weiszmann R, Kwan E, Shu S, Lewis SE, et al. Systematic determination of patterns of gene expression during Drosophila embryogenesis. Genome Biol. 2002;3:research0088.

77. St. Pierre SE, Ponting L, Stefancsik R, McQuilton P, the FlyBase Consortium. FlyBase 102: advanced approaches to interrogating FlyBase. Nucleic Acids Res. 2014;42:D780-8.

78. McQuilton P. St. Pierre SE, Thurmond J, the FlyBase Consortium. FlyBase 101 the basics of navigating FlyBase. Nucleic Acids Res. 2012;40:D706-14.

79. Grumbling G, Strelets V. The FlyBase Consortium. FlyBase: anatomical data, images and queries. Nucleic Acids Res. 2006;34:D484-8. 
80. Kumar S, Konikoff C, Van Emden B, Busick C, Davis KT, Ji S, et al. FlyExpress: visual mining of spatiotemporal patterns for genes and publications in Drosophila embryogenesis. Bioinformatics. 2011;27:3319-20.

81. Lécuyer E, Yoshida H, Parthasarathy N, Alm C, Babak T, Cerovina T, et al. Global analysis of mRNA localization reveals a prominent role in organizing cellular architecture and function. Cell. 2007:131:174-87.

82. Alonso-Barba Jl, Rahman R-U, Wittbrodt J, Mateo JL. MEPD: medaka expression pattern database, genes and more. Nucleic Acids Res. 2015;44:D819-21.

83. Henrich T, Ramialison M, Wittbrodt B, Assouline B, Bourrat F, Berger A, et al. MEPD: a resource for medaka gene expression patterns. Bioinformatics. 2005;21:3195-7.

84. Henrich T. MEPD: a medaka gene expression pattern database. Nucleic Acids Res. 2003;31:72-4.

85. Thompson CL, Ng L, Menon V, Martinez S, Lee C-K, Glattfelder K, et al. A high-resolution spatiotemporal atlas of gene expression of the developing mouse brain. Neuron. 2014;83:309-23

86. Allen Institute for Brain Science. Technical white paper: Allen Developing Mouse Brain Atlas, informatics data processing. 2013. http://help.brain-map.org/ download/attachments/4325389/DevMouse InformaticsDataProcessing.pdf.

87. Allen Institute for Brain Science. Technical white paper: Allen Developing Mouse Brain Atlas. 2010. http://developingmouse.brain-map.org/docs/ Overview.pdf

88. Shimizu H, Kubo A, Uchibe K, Hashimoto M, Yokoyama S, Takada S, et al. The AERO System: a 3D-like approach for recording gene expression patterns in the whole mouse embryo. PLoS One. 2013:8:e75754. Desseyn J-L, editor.

89. Yokoyama S, Ito Y, Ueno-Kudoh H, Shimizu H, Uchibe K, Albini S, et al. A systems approach reveals that the myogenesis genome network is regulated by the transcriptional repressor RP58. Dev Cell. 2009;17:836-48.

90. Richardson L, Venkataraman S, Stevenson P, Yang Y, Moss J, Graham L, et al. EMAGE mouse embryo spatial gene expression database: 2014 update. Nucleic Acids Res. 2014;42:D835-44

91. Richardson L, Stevenson P, Venkataraman S, Yang Y, Burton N, Rao J, et al. EMAGE: Electronic Mouse Atlas of Gene Expression. In: Lewandoski M, editor. Mouse Molecular Embryology. Boston, MA: Springer US; 2014. p. 61-79.

92. Richardson L, Venkataraman S, Stevenson P, Yang Y, Burton N, Rao J, et al. EMAGE mouse embryo spatial gene expression database: 2010 update. Nucleic Acids Res. 2010;38:D703-9.

93. Christiansen JH. EMAGE: A spatial database of gene expression patterns during mouse embryo development. Nucleic Acids Res. 2006;34:D637-41.

94. Diez-Roux G, Banfi S, Sultan M, Geffers L, Anand S, Rozado D, et al. A highresolution anatomical atlas of the transcriptome in the mouse embryo. PLoS Biol. 2011:9:e1000582. Barsh GS, editor.

95. Smith CM, Finger JH, Hayamizu TF, McCright IJ, Xu J, Berghout J, et al. The mouse Gene Expression Database (GXD): 2014 update. Nucleic Acids Res. 2014;42:D818-24.

96. Smith CM, Finger JH, Kadin JA, Richardson JE, Ringwald M. The gene expression database for mouse development (GXD): Putting developmental expression information at your fingertips: GXD: the Mouse Gene Expression Database. Dev Dyn. 2014;243:1176-86.

97. Finger JH, Smith CM, Hayamizu TF, MCCright IJ, Eppig JT, Kadin JA, et al. The mouse Gene Expression Database (GXD): 2011 update. Nucleic Acids Res. 2011;39:D835-41.

98. Smith CM, Finger JH, Hayamizu TF, McCright IJ, Eppig JT, Kadin JA, et al. The mouse Gene Expression Database (GXD): 2007 update. Nucleic Acids Res. 2007:35:D618-23.

99. Schmidt EF, Kus L, Gong S, Heintz N. BAC Transgenic Mice and the GENSAT Database of Engineered Mouse Strains. Cold Spring Harb Protoc. 2013;2013: pdb.top073692.

100. Heintz N. Gene Expression Nervous System Atlas (GENSAT). Nat Neurosci. 2004;7:483.

101. Visel A, Thaller C, Eichele G. GenePaint.org: an atlas of gene expression patterns in the mouse embryo. Nucleic Acids Res. 2004;32:552D-6.

102. Davies JA, Little MH, Aronow B, Armstrong J, Brennan J, Lloyd-MacGilp S, et al. Access and use of the GUDMAP database of genitourinary development. In: Michos O, editor. Kidney Development. Totowa, NJ: Humana Press; 2012. p. 185-201.

103. Harding SD, Armit C, Armstrong J, Brennan J, Cheng Y, Haggarty B, et al The GUDMAP database: an online resource for genitourinary research. Development. 2011;138:2845-53.
104. McMahon AP, Aronow BJ, Davidson DR, Davies JA, Gaido KW, Grimmond S, et al. GUDMAP: the Genitourinary Developmental Molecular Anatomy Project. J Am Soc Nephrol. 2008;19:667-71.

105. James-Zorn C, Ponferrada VG, Jarabek CJ, Burns KA, Segerdell EJ, Lee J, et al. Xenbase: expansion and updates of the Xenopus model organism database. Nucleic Acids Res. 2013;41:D865-70.

106. Bowes JB, Snyder KA, Segerdell E, Gibb R, Jarabek C, Noumen E, et al. Xenbase: a Xenopus biology and genomics resource. Nucleic Acids Res. 2008:36:D761-7.

107. Belmamoune M, Verbeek FJ. Data integration for spatio-temporal patterns of gene expression of zebrafish development: the GEMS database. J Integr Bioinform. 2008:5(2):92.

108. Howe DG, Bradford YM, Conlin T, Eagle AE, Fashena D, Frazer K, et al. ZFIN, the Zebrafish Model Organism Database: increased support for mutants and transgenics. Nucleic Acids Res. 2013:41:D854-60.

109. Bradford Y, Conlin T, Dunn N, Fashena D, Frazer K, Howe DG, et al. ZFIN enhancements and updates to the zebrafish model organism database. Nucleic Acids Res. 2011;39:D822-9.

110. Sprague J, Bayraktaroglu L, Bradford Y, Conlin T, Dunn N, Fashena D, et al. The Zebrafish Information Network: the zebrafish model organism database provides expanded support for genotypes and phenotypes. Nucleic Acids Res. 2007:36:D768-72

111. Lee RYN, Sternberg PW. Building a cell and anatomy ontology of Caenorhabditis elegans. Comp Funct Genomics. 2003:4:121-6.

112. Osumi-Sutherland D, Reeve S, Mungall CJ, Neuhaus F, Ruttenberg A, Jefferis GSXE, et al. A strategy for building neuroanatomy ontologies. Bioinformatics. 2012;28:1262-9.

113. Burger A, Davidson D, Baldock R. Formalization of mouse embryo anatomy. Bioinformatics. 2004;20:259-67.

114. Little MH, Brennan J, Georgas K, Davies JA, Davidson DR, Baldock RA, et al. A high-resolution anatomical ontology of the developing murine genitourinary tract. Gene Expr Patterns. 2007;7:680-99.

115. Segerdell E, Bowes JB, Pollet N, Vize PD. An ontology for Xenopus anatomy and development. BMC Dev Biol. 2008:8:92.

116. Belmamoune M, Verbeek FJ. Developmental Anatomy Ontology of Zebrafish: an integrative semantic framework. J Integr Bioinform. 2007;4:65.

117. Van Slyke CE, Bradford YM, Westerfield M, Haendel MA. The zebrafish anatomy and stage ontologies: representing the anatomy and development of Danio rerio. J Biomed Semantics. 2014;5:12.

\section{Submit your next manuscript to BioMed Central and we will help you at every step:}

- We accept pre-submission inquiries

- Our selector tool helps you to find the most relevant journal

- We provide round the clock customer support

- Convenient online submission

- Thorough peer review

- Inclusion in PubMed and all major indexing services

- Maximum visibility for your research

Submit your manuscript at www.biomedcentral.com/submit 